Research paper

\title{
Magnetic properties of the surface sediments in the Yellow River Estuary and Laizhou Bay, Bohai Sea, China: Implications for monitoring heavy metals
}

\author{
Mingkun Li $^{\text {a,c, }}{ }^{*}$, Shanying Zhu ${ }^{a}$, Tingping Ouyang ${ }^{\text {a,c }}$, Jianhui Tang ${ }^{\text {b, **}}$, Zhihua Tang ${ }^{\mathrm{d}}$ \\ ${ }^{a}$ School of Geography, South China Normal University, Guangzhou 510631, PR China \\ ${ }^{\mathrm{b}}$ Key Laboratory of Coastal Environmental Processes and Ecological Remediation, Yantai Institute of Coastal Zone Research, Chinese Academy of Sciences, Yantai \\ 264003, PR China \\ ${ }^{\mathrm{c}}$ Key Laboratory of Ocean and Marginal Sea Geology, Guangzhou Institute of Geochemistry, Chinese Academy of Sciences, Guangzhou 510640, PR China \\ ${ }^{\mathrm{d}}$ Integrated Technology Center, Guangzhou Institute of Energy Conversion, Chinese Academy of Sciences, Guangzhou 510640, PR China
}

\section{A R T I C L E I N F O}

Editor: Dr. CHEN. LingXin

\section{Keywords:}

Heavy metals

Environmental magnetism

Yellow River Estuary

Laizhou Bay

Marine sediment

\begin{abstract}
A B S T R A C T
The Yellow River Estuary (YRE) and adjacent Laizhou Bay (LB) encounter eco-environmental risks caused by heavy metals (HMs) pollution. Here magnetic measurements were performed on 239 surface sediment samples from the YRE and LB to establish a rapid and effective method for detecting HMs. Magnetite, maghemite, and hematite coexist in the sediments. The distributions of magnetic minerals are dominated by sediment sources (Yellow River in northern and western LB, and rivers in southern and eastern coastal LB), and the anticlockwise water current. Compared to the background values, Cd content is enriched for all samples, while $\mathrm{Co}, \mathrm{Cr}, \mathrm{Ni}, \mathrm{Cu}$, $\mathrm{Zn}$, and $\mathrm{Pb}$ contents are lower for most samples. The low pollution load indexes (PLI) of HMs $(<1-1.56)$ indicate the unpolluted to moderately polluted status, while the muddy area is the most polluted. The principal component analysis indicates that $\mathrm{Co}, \mathrm{Cr}, \mathrm{Ni}, \mathrm{Cu}$, and $\mathrm{Zn}$ are mainly from natural weathering substances, while $\mathrm{Cd}$ and $\mathrm{Pb}$ are anthropogenic. Contents of fine-grained sediments and magnetic particles are positively correlated to $\mathrm{Co}, \mathrm{Ni}, \mathrm{Cu}, \mathrm{Zn}$, and PLI. The high-risk $\mathrm{Co}, \mathrm{Ni}, \mathrm{Cu}$, and $\mathrm{Zn}$ regions can be quickly delineated with the frequencydependent susceptibility.
\end{abstract}

\section{Introduction}

Estuaries and their adjacent waters are vital for transporting the nature-derived and anthropogenic materials to the sea. With the rapid economic development and population growth near the coasts over the past decades, the estuaries and surroundings have accumulated substantial amounts of heavy metals (HMs) due to industrialization and urbanization activities. As a result, marine ecosystems are under serious threat (Li et al., 2017; Rubio et al., 2000). In China, the HMs are mainly concentrated in sediments of rivers and seas in the northeastern and northern China (Zhang and Shao, 2013). For example, the elevated cadmium (Cd) and mercury $(\mathrm{Hg})$ concentrations in an estuary of northern China are ascribed to copper mining and vehicle emissions, respectively (Li et al., 2017). Therefore, rapidly assessing the contamination of HMs and delineate the high environmental risk areas in estuaries and shallow seas is crucial.

The Yellow River Estuary (YRE) and adjacent semi-closed Laizhou Bay (LB) forms one of the most important sea-land interaction zones in northern China (Fig. 1), on account of the largest sediment runoff from the Yellow River (YR), and the complex water currents. The LB is surrounded by the Dongying, Weifang, and Laizhou Port Industrial Zones (Xu et al., 2015) (Fig. 1c); hence it faces high ecological risks driven by HMs contents (e.g., Cd and Hg) (Cheng et al., 2017; Hu et al., 2017; Li et al., 2018; Liang et al., 2018; Rao et al., 2018; Wang et al., 2017; Xu et al., 2015; Zhang and Gao, 2015; Zhuang and Gao, 2014). Previous studies attributed the enrichments of HMs to the frequent discharge of industrial wastewaters and untreated or insufficiently-treated sewage into the surrounding rivers and finally into the bay (Zhuang and Gao, 2014). Notably, the HM concentrations in the YRE and LB sediments vary spatially and temporally because the sediment discharge from

\footnotetext{
* Correspondence to: South China Normal University, 55 Zhongshan Road West, Tianhe District, Guangzhou 510631, PR China.

** Correspondence to: South China Normal University, 17 Chunhui Road, Laishan District, Yantai 264003, PR China.

E-mail addresses: limk@m.scnu.edu.cn (M. Li), jhtang@yic.ac.cn (J. Tang).
} 
adjacent rivers changes with seasons and the progressively enhanced anthropogenic impacts (Liu et al., 2019; Rao et al., 2018; Wang et al., 2017). Therefore, it is necessary to investigate the HM concentrations and evaluate their enrichment status frequently. Rapid and effective methods are needed to improve the efficiency of HM monitoring.

Environmental magnetism, known as a rapid, economical, and nondestructive technology, has been widely used to detect the HM pollution within soils, dust, and sediments (e.g., Chaparro et al., 2017; Dong et al., 2014; Hofman et al., 2013; Jordanova et al., 2008; Wang et al., 2020; Yang et al., 2007; Zhang et al., 2011). For urban soils and river samples, the positive correlation between the Tomlinson pollution load index (PLI) and magnetic concentration-related parameters for the polluted samples might indicate that the magnetic parameters are useful for predicting the pollution caused by some HMs (Karimi et al., 2011; Wang and Qin, 2005; Zhang et al., 2011). The air comprehensive pollution index could be fitted using a linear regression equation established by elements and magnetic susceptibility for a sediment core in a water reservoir (Ma et al., 2015). Regression equations between elements and magnetic parameters could be established to estimate the concentrations of the anthropogenic metal elements in atmospheric particles (Shu et al., 2001). For the modern coastal sediments, the increased magnetic concentrations are always coupled with the elevated PLI values and human-induced elements (Chaparro et al., 2017; Yang et al., 2019; Zhu et al., 2016). For instance, the anhysteretic remanence susceptibility $\left(\chi_{\text {ARM }}\right)$ and the ratio between $\chi_{\text {ARM }}$ and magnetic susceptibility $(\chi)$ were used as indicators of environmental pollution in the nearshore area of the East China Sea (Wang et al., 2020). In addition, the method is effective in detecting the enhanced influences of human activities on estuaries and coasts. The impact of onshore iron ore mining on the ancient offshore sedimentation in the Arabian Sea was detected using the magnetic approach (Sebastian et al., 2017).

The positively linear correlations between magnetic parameters (e. g., frequency-dependent susceptibility) and $\mathrm{HMs}(\mathrm{Cd}, \mathrm{Co}, \mathrm{Cr}, \mathrm{Ni}, \mathrm{Pb}$, and $\mathrm{Zn}$ ) were found from the core Z07 close to the old YRE (Chen et al., 2020) (Fig. 1c), which implies the magnetic approach is probably suitable in rapidly evaluating the HMs in the region. The core Z07 spans the period of 1999-2007 A.D. As the pollution of HMs is gradually spreading from land to sea, more studies concerning the whole bay, not only one site are needed. In this study, we performed magnetic and HM analysis on 239 surface sediments collected from the YRE and LB. The objectives of this paper are to (1) evaluate the enrichment of HMs and their sources, and (2) identify proper magnetic parameters to rapid detect HMs if possible.

\section{Materials and methods}

\subsection{Study area and sampling}

The LB located between the YRE and Shandong Peninsula (Fig. 1) was formed in 1885 due to the relocation of the YR channel. The abandoned YRE was formed with the estuary evolution and the YRE's last change from the old YRE to the modern one in 1996 (Fig. 1). The bay is approximately $96 \mathrm{~km}$ wide and $7000 \mathrm{~km}^{2}$ in area with gradually deepening water $(0-20 \mathrm{~m})$ from southwest to northeast (Fig. 1) (Compiling Committee of Records of China Bays, 1991; Liu and Wang, 2013; Qin et al., 1985). The semicircle bay is linked to more than ten local streams (Fig. 1) and is bounded by a broad plain covered with Quaternary sediments to the west and south and a mountainous area (the Shandong Peninsula) with granitoid to the east (Compiling Committee of Records of China Bays, 1991). The YR, the second largest river

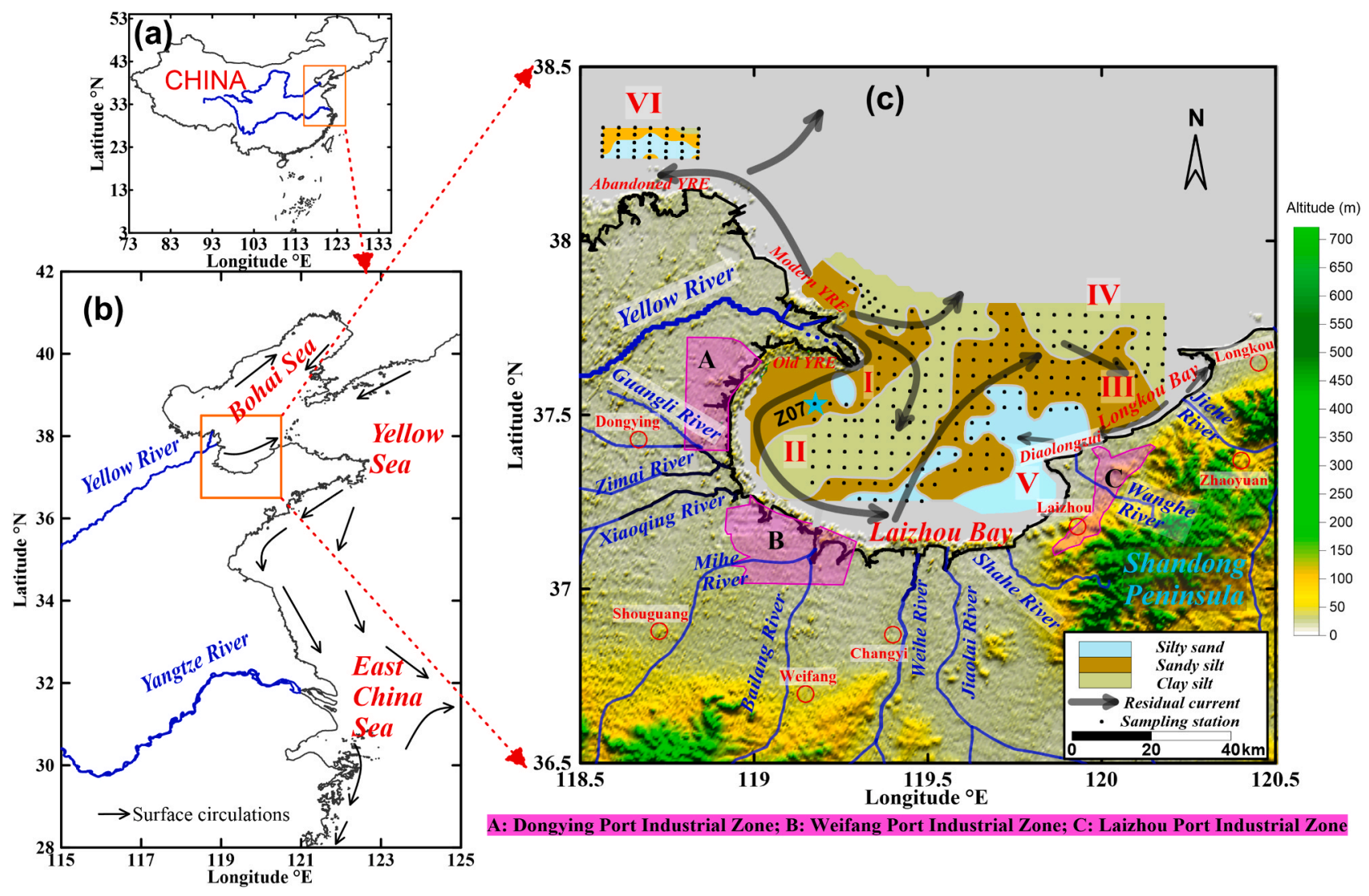

Fig. 1. (a) Map of China. (b) The seas with surface circulations in eastern China, and the location of Laizhou Bay. (c) Location of the study area and the adjacent geomorphology, rivers, industrial zones, and sampling sites. The arrows in (c) stand for water currents redrawn from Qiao et al. (2010); Qin et al. (1985). In the estuarial area, the abandoned (before 1976), old (1976-1996), and modern Yellow River Estuary (YRE) (1996-present) are marked. According to sediment types, the Laizhou Bay is divided into five zones, and the abandoned YRE is Zone VI (see the text). 
in the world in terms of annual sediment discharge to oceans (ca.1.1 $\left.\times 10^{9} \mathrm{t} / \mathrm{a}\right)$ (Milliman and Meade, 1983), is the most significant sediment contributor to the LB (Compiling Committee of Records of China Bays, 1991). Driven by coastal currents and tides, fluvial substances are mostly deposited and migrated at the bay in bed-load and suspended-load (Qiao et al., 2008, 2010; Qin and Li, 1982). As a result, the mud area was formed in the central bay (Qiao et al., 2010). The irregular semidiurnal tides frequently erode the modern YRE and south coast, and the erosion materials are transported to out-seas by residual currents in the form of suspended-load (Fig. 1).

From September to October 2012, surface sediment samples of the LB (204 samples) and the abandoned YRE (35 samples) were collected using a stainless steel box corer in a research vessel (Fig. 1). The water depths of all sampling stations were between 5.0 and $19.2 \mathrm{~m}$.

\subsection{Grain size measurements}

After gathering the sediment samples (see Section 2.1), less than $1 \mathrm{~g}$ of the freeze-dried sediments was rinsed using hot hydrogen peroxide $\left(10 \% \mathrm{H}_{2} \mathrm{O}_{2}, \sim 80{ }^{\circ} \mathrm{C}\right)$ to remove organic matters. Then, the samples were treated with hydrochloric acid $\left(1 \mathrm{~N} \mathrm{HCl}, \sim 80^{\circ} \mathrm{C}\right)$ to remove carbonates. The $\mathrm{pH}$ value of the solution of the residual sample was adjusted to 7 by repeatedly rinsing the samples with distilled water. Ultrasounds with sodium metaphosphate $\left[\left(\mathrm{NaPO}_{3}\right)_{6}\right]$ solutions were applied to the samples to eliminate the aggregated particles. Each sample's grain size was analyzed using a Malvern Mastersizer 2000F laser diffraction particle analyzer (range $0.02-2000 \mu \mathrm{m}$ ). Here the nomenclature of sedimentary types was in accordance with Shepard (1954).

\subsection{Measurements of HMs}

The sediment samples were freeze-dried and pulverized in an agate mortar to 100 mesh. Aliquot of sediments $(0.2500 \mathrm{~g} \pm 0.0001)$ were digested in Teflon tubes with a mixed solution $\left(\mathrm{HNO}_{3}\right.$ : $\mathrm{HF}: \mathrm{HClO}_{4}, 5: 3: 1$ by volume) in a microwave digestion instrument at $180{ }^{\circ} \mathrm{C}$ for $6 \mathrm{~h}$ (Tank Basci, Sineo Microwave Chemistry Technology Co., LTD, China). The digested solutions were then baked to nearly dry at $140{ }^{\circ} \mathrm{C}$ for $2 \mathrm{~h}$. Two milliliters of concentrated $\mathrm{HNO}_{3}$ was added to re-dissolve the residues at $120{ }^{\circ} \mathrm{C}$. The solutions were then diluted to $100 \mathrm{~mL}$ with deionized water. Seven HMs, including cobalt (Co), chromium (Cr), nickel (Ni), copper $(\mathrm{Cu})$, zinc $(\mathrm{Zn}), \mathrm{Cd}$, and lead $(\mathrm{Pb})$, were measured using the inductively coupled plasma mass spectrometry (ICP-MS, Perkin Elmer NexIon 300Q, USA). All of the tests were performed under the pulse mode after five times of dilution for the elements, which yielded a limit of detection (LOD) better than $0.01 \mathrm{ng} / \mathrm{mL}$, and a limit of quantification (LOQ) better than $0.03 \mathrm{ng} / \mathrm{mL}$. All of the digested solutions were measured three times, and the relative standard deviation (RSD) was less than $2.5 \%$ for all samples. The recovery rates of the seven elements were all above $85 \%$.

Following previous studies (Angulo, 1996; Salomons and Förstner, 1984; Zhang et al., 2011), this study applied the pollution load index (PLI) to comprehensively evaluate the metal induced pollution. The contamination factor $(\mathrm{CF})$ was calculated as $\mathrm{CF}=\mathrm{C}_{\text {metal }} / \mathrm{C}_{\text {background value }}$ for $\mathrm{Co}, \mathrm{Cr}, \mathrm{Ni}, \mathrm{Cu}, \mathrm{Zn}, \mathrm{Cd}$, and $\mathrm{Pb}$. The average values of metals of soils in Shandong province were selected as the background values (China National Environmental Monitoring Center, 1990). The formula for PLI can be expressed as PLI $=\sqrt[n]{\mathrm{CF} 1 \times \mathrm{CF} 2 \times \mathrm{CF} 3 \ldots \times \mathrm{CFn}}$ (Tomlinson et al., 1980). The PLI values and implications are as follows: PLI $=0$ indicates background concentration; $0<$ PLI $<1$ indicates unpolluted; $1<$ PLI $<2$ indicates moderately polluted to unpolluted; $2<$ PLI $<3$ indicates moderately polluted; $3<$ PLI $<4$ indicates moderately to highly polluted; $4<$ PLI $<5$ indicates highly polluted; PLI $>5$ indicates very highly polluted.

\subsection{Magnetic measurements}

Before operating magnetic measurements, all bulk samples were freeze-dried, pulverized, and put into non-magnetic $2 \times 2 \times 2 \mathrm{~cm}^{3}$ cubic boxes. Magnetic susceptibility is roughly proportional to the concentration of ferrimagnetic minerals (especially for magnetite) and can be affected by magnetic particles (Thompson and Oldfield, 1986). The low-field magnetic susceptibility was measured at both low $(976 \mathrm{~Hz})$, and high $(15,616 \mathrm{~Hz})$ frequencies using a Kappabridge MFK1-FA and was normalized by volumetric weight to obtain the mass-specific magnetic susceptibility ( $\chi_{\mathrm{lf}}$ and $\chi_{\mathrm{hf}}$, respectively) for all samples. The frequency-dependent susceptibility $\chi_{\mathrm{fd}}$ (reflecting the content of ultrafine magnetic particles) and $\chi_{\mathrm{fd}} \%$ (reflecting the contribution of superparamagnetic (SP) particles to magnetic susceptibility) were calculated using the equations: $\chi_{\mathrm{fd}}=\chi_{\mathrm{lf}}-\chi_{\mathrm{hf}}$, and $\chi_{\mathrm{fd}} \%=100 \times$ $\left(\chi_{\mathrm{lf}}-\chi_{\mathrm{hf}}\right) / \chi_{\mathrm{lf}}($ Maher, 1986). Anhysteretic remanence (ARM), which is sensitive to single domain (SD) particles (Maher, 1988), was imparted at a maximum peak alternating field of $100 \mathrm{mT}$ with a $0.05 \mathrm{mT}$ direct current (DC) bias field using a D-2000 AF Demagnetizer and measured using a JR-6A magnetometer for all samples. ARM susceptibility ( $\chi_{\text {ARM }}$ ) was calculated by dividing ARM with the DC bias field $(0.05 \mathrm{mT})$. Saturation isothermal remanence (SIRM) is also a magnetic mineral concentration-dependent parameter without SP particles' effect compared to magnetic susceptibility (Thompson and Oldfield, 1986). Hard isothermal remanence (HIRM) is exclusively dependent on the contents of the high-coercivity components (e.g., hematite and goethite) (Robinson and Sahota, 2000). The S-ratio reflects the relative contents of high and low coercivity components within a mixed magnetic mineral assemblage (Robinson and Sahota, 2000). SIRM, IRM $-100 \mathrm{mT}$, and IRM $_{-300 \mathrm{mT}}$ were imparted at a DC field of $2 \mathrm{~T}\left(\mathrm{IRM}_{2 \mathrm{~T}}\right.$ regarded as SIRM in the present study) and backfields of $100 \mathrm{mT}$ and $300 \mathrm{mT}$ generated by an IM-10-30 Pulse Magnetizer, and were measured using a JR-6A magnetometer sequentially. The HIRM and $\mathrm{S}_{-100}$ were calculated using: $H I R M=\left(I_{R M}-300 \mathrm{mT}+\right.$ SIRM$) / 2$ (Bloemendal et al., 1988; Robinson, 1986$)$ and $\mathrm{S}_{-100}(\%)=100 \% \times\left(\mathrm{SIRM}-\mathrm{IRM}_{-100 \mathrm{mT}}\right) /(2 \times \mathrm{SIRM})$ (Bloemendal et al., 1992), respectively. The $\chi_{\mathrm{ARM}} / \mathrm{SIRM}$ was used to estimate the granularity of ferrimagnetic particles, and the higher value corresponds to more content of fine magnetic particles (Dong et al., 2014; Kim et al., 2013; Maher, 1988, 2007).

To better understand the magnetic properties, 21 representative samples were chosen for further magnetic measurements. Variation of magnetic susceptibility with temperature ( $\kappa$-T curve) was measured from room temperature to $700{ }^{\circ} \mathrm{C}$ using a CS4 high-temperature unit attached to the MFK1-FA instrument. All the above-described analyses were conducted at the Guangzhou Institute of Geochemistry, Chinese Academy of Sciences.

For the 21 representative samples, the measurements of the hysteresis loop, IRM acquisition curve, and backfield demagnetization curve were performed using a Princeton Measurements Corp. Micromag 3900 Vibrating Sample Magnetometer (VSM) at the Third Institute of Oceanography, Ministry of Natural Resources of China. Thus, hysteresis parameters, including the coercivity $\left(B_{c}\right)$, coercivity of remanence $\left(B_{c r}\right)$, saturation remanent magnetization $\left(\mathrm{M}_{\mathrm{rs}}\right)$, and saturation magnetization $\left(\mathrm{M}_{\mathrm{S}}\right)$, were calculated to draw the Day plot (Day et al., 1977). Contributions of different magnetic components were quantified by cumulative log-Gaussian (CLG) analysis for IRM acquisition curves using the IRMUNMIX2_2 and IRM_CLG1 routines (Heslop et al., 2002; Kruiver et al., 2001). The first-order reversal curve (FORC) was measured using the same instrument at the Paleo \& Environment Magnetism Lab, Australian National University (Zhao et al., 2015). Based on the iFORC 2 software, the induced field and smoothing factor were set as $[500 \mathrm{mT}$, $-500 \mathrm{mT}$ ] and 3 , respectively.

\subsection{SEM-EDS analyses for extracted magnetic minerals}

Five representative samples were air-dried to separate the magnetic 
particles. The magnet was separated from the sample by a thin film in the magnetic separation process. The extracted magnetic minerals were analyzed using a scanning electron microscope with an energy dispersive spectrometer (SEM-EDS). We made observations of magnetic extracts using a Quanta FEG 250 Field-emission SEM with a magnification of $1000 \times$ and an acceleration voltage of $20 \mathrm{kA}$. Chemical spectra of minerals were obtained using an Oxford Instruments Ltd. INCA X-MAX50 EDS. In each sample, one or two particles were photographed and scanned with the chemical spectra.

\subsection{Statistical and spatial analyses}

The Kriging method was used in the spatial interpolation. Spatial distribution and contour maps of every parameter were generated by Golden Surfer 10. Correlation and principal component analyses among magnetic parameters, HM contents, and grain sizes were performed using the IBM SPSS Statistics 19.

\section{Results}

\subsection{Grain-size distributions and sediment zones}

The clay $(<4 \mu \mathrm{m})$, silt $(4-63 \mu \mathrm{m})$, and sand $(>63 \mu \mathrm{m})$ contents of the measured samples are $1.8-61.7 \%, 23.2-77.1 \%$, and $0-75 \%$, respectively (Fig. 2a-c). The clay and silt are consistent, and their values are relatively high in the middle of the bay along the northwest-northnorthwest axis and the northeastern part of the bay (Fig. 2a and b). The sand content is the highest in the river mouth, the southern and southeastern LB, and the abandoned YRE (Fig. 2c). According to the classification criteria proposed by Shepard (1954), the main sediment
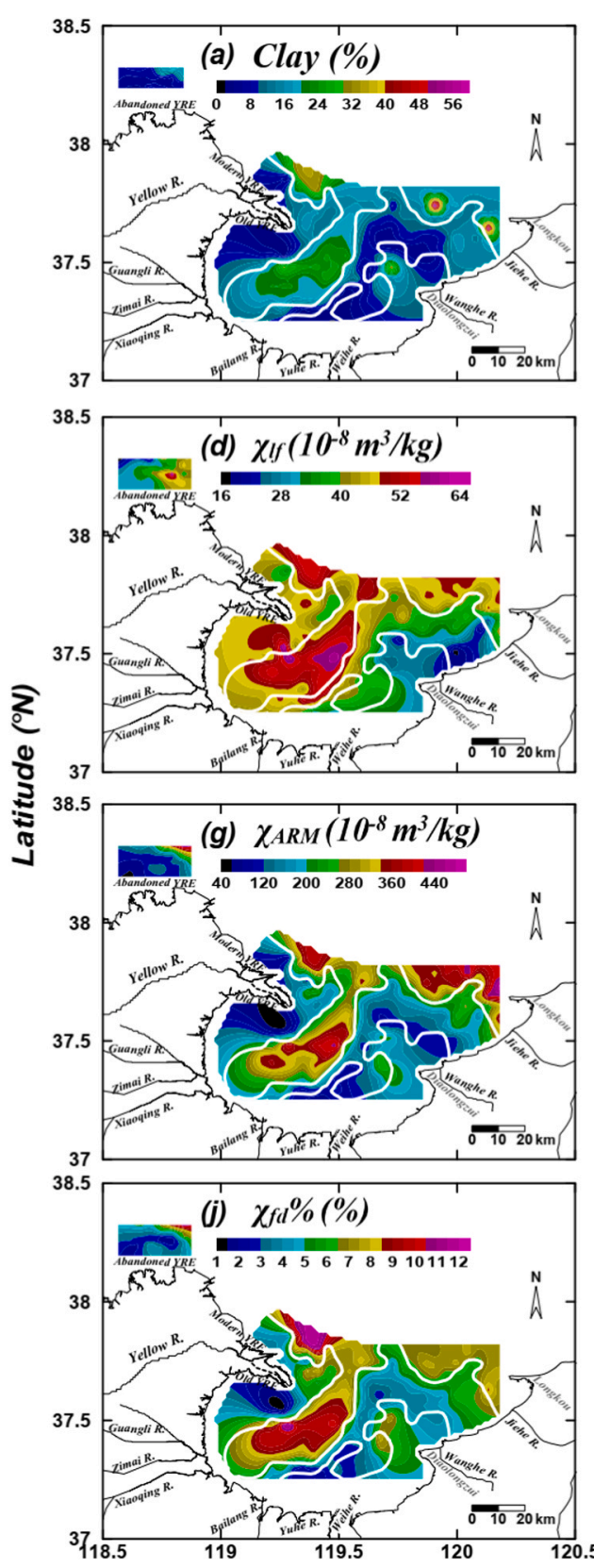
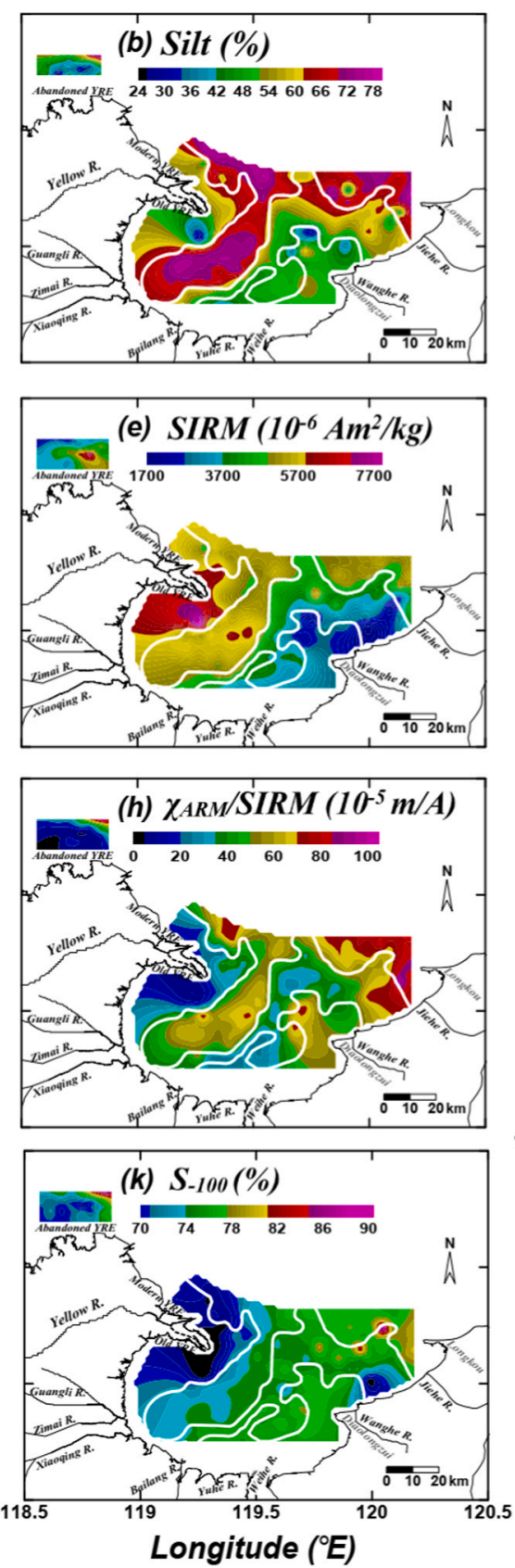
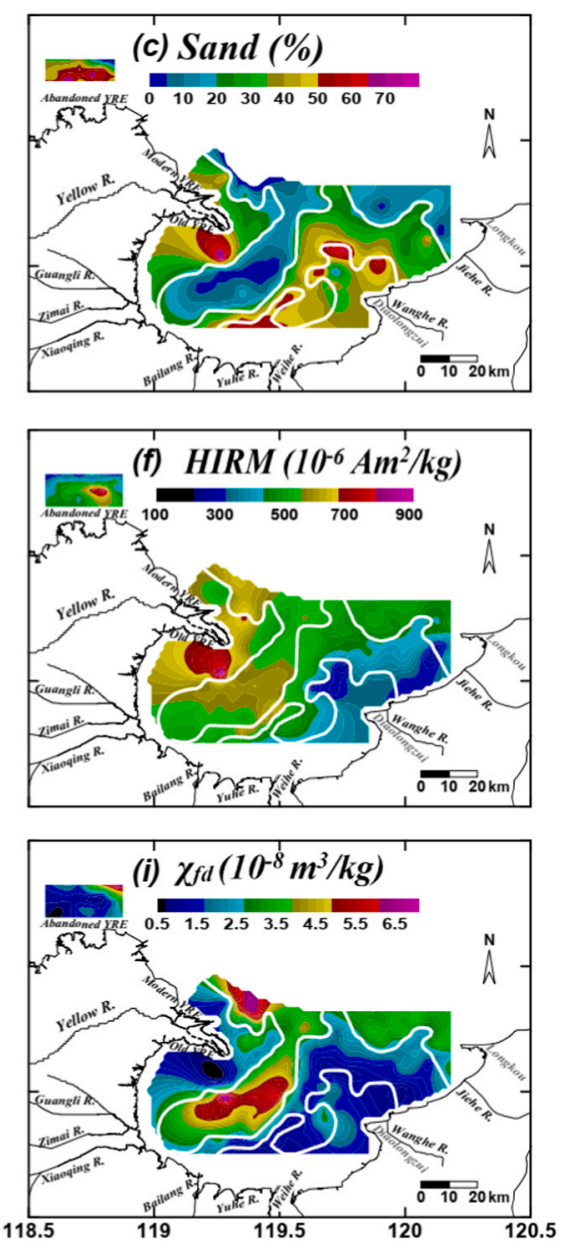

Fig. 2. Contour maps of (a) clay (\%), (b) silt (\%), (c) sand (\%), (d) $\chi_{\mathrm{lf}}\left(10^{-8} \mathrm{~m}^{3} / \mathrm{kg}\right)$, (e) SIRM $\left(10^{-6} \mathrm{Am}^{2} / \mathrm{kg}\right),(\mathrm{f}) \mathrm{HIRM}\left(10^{-6} \mathrm{Am}{ }^{2} / \mathrm{kg}\right),(\mathrm{g}) \chi_{\mathrm{ARM}}\left(10^{-8} \mathrm{~m}^{3} / \mathrm{kg}\right),(\mathrm{h})$ $\chi_{\mathrm{ARM}} / \operatorname{SIRM}\left(10^{-5} \mathrm{~m} / \mathrm{A}\right)$, (i) $\chi_{\mathrm{fd}}\left(10^{-8} \mathrm{~m}^{3} / \mathrm{kg}\right)$, (j) $\chi_{\mathrm{fd}} \%(\%)$, and $(\mathrm{k}) \mathrm{S}_{-100}(\%)$. 
types of the study area are clayey silt (YT), silty sand (TS), and sandy silt (ST) (Fig. 1).

Given the non-negligible grain-size effects on elements in the LB (Zhuang and Gao, 2014), we classify the study area into six sedimentary zones (Fig. 1, Table 1) (Compiling Committee of Records of China Bays, 1991; Qin et al., 1985). The YR mouth, mainly contains ST, is classified as Zone I. The adjacent region mainly filled with YT, known as the mud area (Qiao et al., 2010), is classified as Zone II. The central area with ST and southeastern area with TS are classified as Zones III and V, respectively. The other mud area filled with YT in the northeastern bay is classified as Zone IV. For comparison, the abandoned YRE is classified as Zone VI.

\subsection{Magnetic features and magnetic mineral distributions}

\subsubsection{Species and morphology of magnetic minerals}

The $\kappa$ - $\mathrm{T}$ curve plays a vital role in identifying magnetic minerals (Dunlop and Özdemir, 1997). According to the variation behavior of the $\kappa$-T curves, the 21 samples are categorized into two groups (Fig. 3a and b). The distinct loss of susceptibility observed at about $570-580{ }^{\circ} \mathrm{C}$ (Curie temperature of magnetite) for all samples (Fig. 3a and b) reflects the presence of magnetite (Dunlop and Özdemir, 1997; Thompson and Oldfield, 1986). Moreover, the significant declines of 19 heating curves above $600{ }^{\circ} \mathrm{C}$ (Fig. 3a) suggest the existence of hematite (Dunlop and Özdemir, 1997; Thompson and Oldfield, 1986). The decrease of susceptibility from about $300-400{ }^{\circ} \mathrm{C}$ probably indicates the transformation of maghemite to hematite (Fig. 3a) (Dunlop and Özdemir, 1997; Gattacceca et al., 2014). In the heating curves, noticeable humps that occurred at about $500{ }^{\circ} \mathrm{C}$ should be the combined results of new ferrimagnetic minerals generation and Hopkinson effect generated by SD particles due to heating (Fig. 3a and b) (Dunlop and Özdemir, 1997; van Velzen and Dekkers, 1999). The elevated magnetic susceptibility during the cooling process confirms the production of new strong magnetic minerals during the heating process (Fig. $3 \mathrm{a}$ and $\mathrm{b}$ ).

Particle sizes of the extracted magnetic minerals of the adjacent rivers and the bay are several tens of $\mu \mathrm{m}$ (Fig. 4) (Li et al., 2020). There are angular, subangular, and spherical particles in morphology. The chemical constituents of the magnetic minerals are iron ( $\mathrm{Fe})$, and oxygen (O). The silicon ( $\mathrm{Si})$, aluminum ( $\mathrm{Al}$ ), potassium $(\mathrm{K})$, magnesium $(\mathrm{Mg})$, and calcium (Ca) are probably from the adherent clay minerals onto the magnetite (Fig. 4c and d).

\subsubsection{Hysteresis characteristics of magnetic minerals}

The patterns of the hysteresis loop and FORC primarily reflect the magnetic domain states and magnetic mineral species (Pike et al., 2001; Roberts et al., 1995, 2018; Tauxe et al., 1996). All measured hysteresis loops exhibit thin "normal" shapes without "wasp-waist" or "potbelly" characteristics (Fig. 3c), indicating that all measured samples predominantly contain low-coercivity minerals (Roberts et al., 1995; Tauxe et al., 1996). Furthermore, all measured loops close at about $600 \mathrm{mT}$, suggesting the presence of high coercivity magnetic components (e.g., hematite) (Abrajevitch et al., 2015). In all of the measured FORC diagrams, the contour lines end at $B_{c}=40-60 \mathrm{mT}$ with a peak at $B_{c}$
$<20 \mathrm{mT}$ and a medium coercivity tail, indicating the existence of weakly interacting SD grains (Pike et al., 2001) (Fig. 3d). Besides, the wide vertical distribution of $\mathrm{B}_{\mathrm{u}}$ is the signal of "pseudo-single-domain" ("PSD," or "vortex") grains (Roberts et al., 2000, 2017). Hence, the FORC diagrams reflect the mixed magnetite assemblages of SD and "PSD" grains.

Day and Dearing plots are widely used for discrimination of domain state for ferrimagnetic minerals (Day et al., 1977; Dearing et al., 1997). Frequency-dependent susceptibility applied in the Dearing plot was measured using the Bartington instrument. To eliminate the influence generated by different applied frequencies using different types of magnetic susceptibility instruments, Hrouda (2011) presented the following conversion formula:

$\chi \mathrm{FB} \%=\frac{\ln 10}{\ln f_{\mathrm{mHF}}-\ln f_{\mathrm{mLF}}} \chi \mathrm{fd} \%$

where $\chi_{\mathrm{FB}} \%$ is the frequency-dependent susceptibility used in the Dearing plot, the parameters $f_{\mathrm{mHF}}, f_{\mathrm{mLF}}$, and $\chi_{\mathrm{fd}} \%$ are the values of high, low frequency, and frequency-dependent susceptibility measured by Kappabridge MFK1-FA in this study, respectively. All points in the Day plot are located in the area of "PSD" as well as between lines of MD-SD and SD-10 nm SP mixtures (Dunlop, 2002) (Fig. S1). Most points in the Dearing plot are distributed in the area of the stable SD (SSD) with 10-50\% SP particles (Fig. S1). Magnetic mineral grain-sizes are different for the six zones. Magnetic mineral particles in Zones V and II are the coarsest and finest particles, respectively. Variations of magnetic mineral granularity in the YREs (Zones I and VI) and Zone III are extensive. Zones II and IV, areas with the most abundant fine-grained sediments, have the maximum amount of fine magnetic particles (SP and SD).

\subsubsection{Quantification of different magnetic components}

Shapes of IRM acquisition curves could roughly indicate "hard" (high-coercivity minerals, e.g., hematite) or "soft" (low-coercivity minerals, e.g., magnetite) magnetic minerals for a sample (Dunlop and Özdemir, 1997). Moreover, the CLG analysis of the IRM acquisition curve could be utilized to quantify magnetic coercivity components (Heslop et al., 2002; Robertson and France, 1994). All measured IRM acquisition curves reach about $77-85 \%$ saturation at $100 \mathrm{mT}$ and about 92-95\% saturation at $300 \mathrm{mT}$ (Fig. 3e). The curves of all measured samples are not saturated until $\sim 750 \mathrm{mT}$, indicating the contribution of high-coercivity magnetic minerals (Fig. 3e). The range of $\mathrm{B}_{\mathrm{cr}}$ for all measured samples is from 30.41 to $43.24 \mathrm{mT}$. These results reveal that low coercivity magnetic minerals predominate all samples, and some high coercivity magnetic components coexist. Four magnetic components $\left(\mathrm{C}_{1-4}\right)$ are identified from the CLG analysis of IRM acquisition curves (Fig. 3f). $C_{1}$ and $C_{2}$ with low $B_{1 / 2}$ might be magnetite with different grain sizes (Abrajevitch et al., 2009; Heslop et al., 2002; Ouyang et al., 2015). The $\mathrm{B}_{1 / 2}$ and $\mathrm{DP}$ of $\mathrm{C}_{3}$ range from 46 to $79 \mathrm{mT}$ and from 0.24 to 0.38 , respectively, meaning that $C_{3}$ might be a mixture of maghemite and partially oxidized magnetite (Kruiver et al., 2001; Spassov et al., 2003). $\mathrm{C}_{4}$ with the highest $\mathrm{B}_{1 / 2}(389-631 \mathrm{mT})$ and narrow DP could be hematite (Abrajevitch et al., 2015; Robertson and France, 1994), which is consistent with the results of the $\kappa$-T curves.

Table 1

Summary of grain sizes for surface sediments from each zone within the Yellow River Estuary and Laizhou Bay.

\begin{tabular}{|c|c|c|c|c|c|c|c|}
\hline \multicolumn{2}{|l|}{ Zone (N) } & \multirow{2}{*}{$\frac{\mathrm{I}(19)}{\mathrm{ST}}$} & \multirow{2}{*}{$\frac{\mathrm{II}(61)}{\mathrm{YT}}$} & \multirow{2}{*}{$\frac{\text { III (73) }}{\text { ST }}$} & \multirow{2}{*}{$\frac{\mathrm{IV}(24)}{\mathrm{YT}}$} & \multirow{2}{*}{$\frac{\mathrm{V}(26)}{\mathrm{TS}}$} & \multirow{2}{*}{$\frac{\text { VI (35) }}{\text { Mixed }}$} \\
\hline Sediment & & & & & & & \\
\hline \multirow[t]{2}{*}{ Clay/\% } & Mean \pm STD & $12.8 \pm 4.70$ & $21.5 \pm 4.1$ & $11.31 \pm 4.2$ & $21.6 \pm 12.4$ & $5.7 \pm 3.8$ & $8.2 \pm 4.3$ \\
\hline & Max-Min & $20.7-1.8$ & $32.8-15.0$ & $18.4-3.6$ & $61.7-14.2$ & $14.9-1.9$ & $19.7-3.5$ \\
\hline \multirow[t]{2}{*}{ Silt/\% } & Mean \pm STD & $57.9 \pm 10.7$ & $69.8 \pm 3.0$ & $56.4 \pm 6.1$ & $67.6 \pm 9.2$ & $41.6 \pm 5.9$ & $46.8 \pm 9.4$ \\
\hline & Max-Min & $67.7-23.2$ & $74.8-60.8$ & $69.7-44.8$ & $77.1-37.6$ & $48.2-26$ & $73.8-27.3$ \\
\hline \multirow[t]{2}{*}{ Sand/\% } & Mean \pm STD & $29.3 \pm 14.3$ & $8.7 \pm 4.7$ & $32.4 \pm 8.8$ & $10.8 \pm 4.9$ & $52.7 \pm 6.5$ & $45.0 \pm 13.0$ \\
\hline & Max-Min & $75-17.5$ & $19.6-1.6$ & $47.7-16.9$ & $17.9-0$ & $69.8-42.9$ & $69.1-9.2$ \\
\hline
\end{tabular}

N: Sample number, ST: Sandy silt, YT: Clay silt, TS: Silty sand, STD: Standard deviation. 

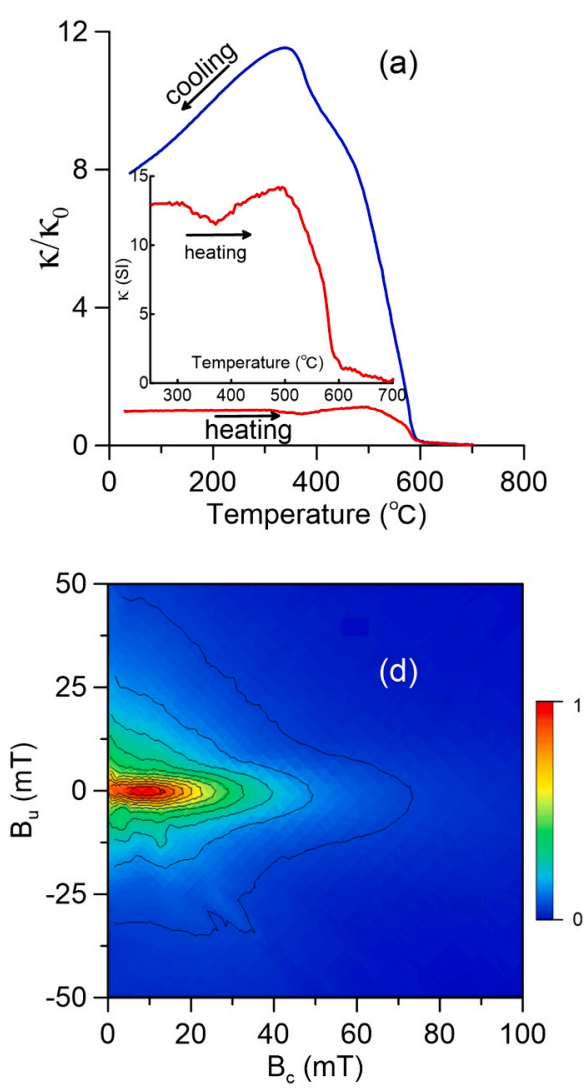
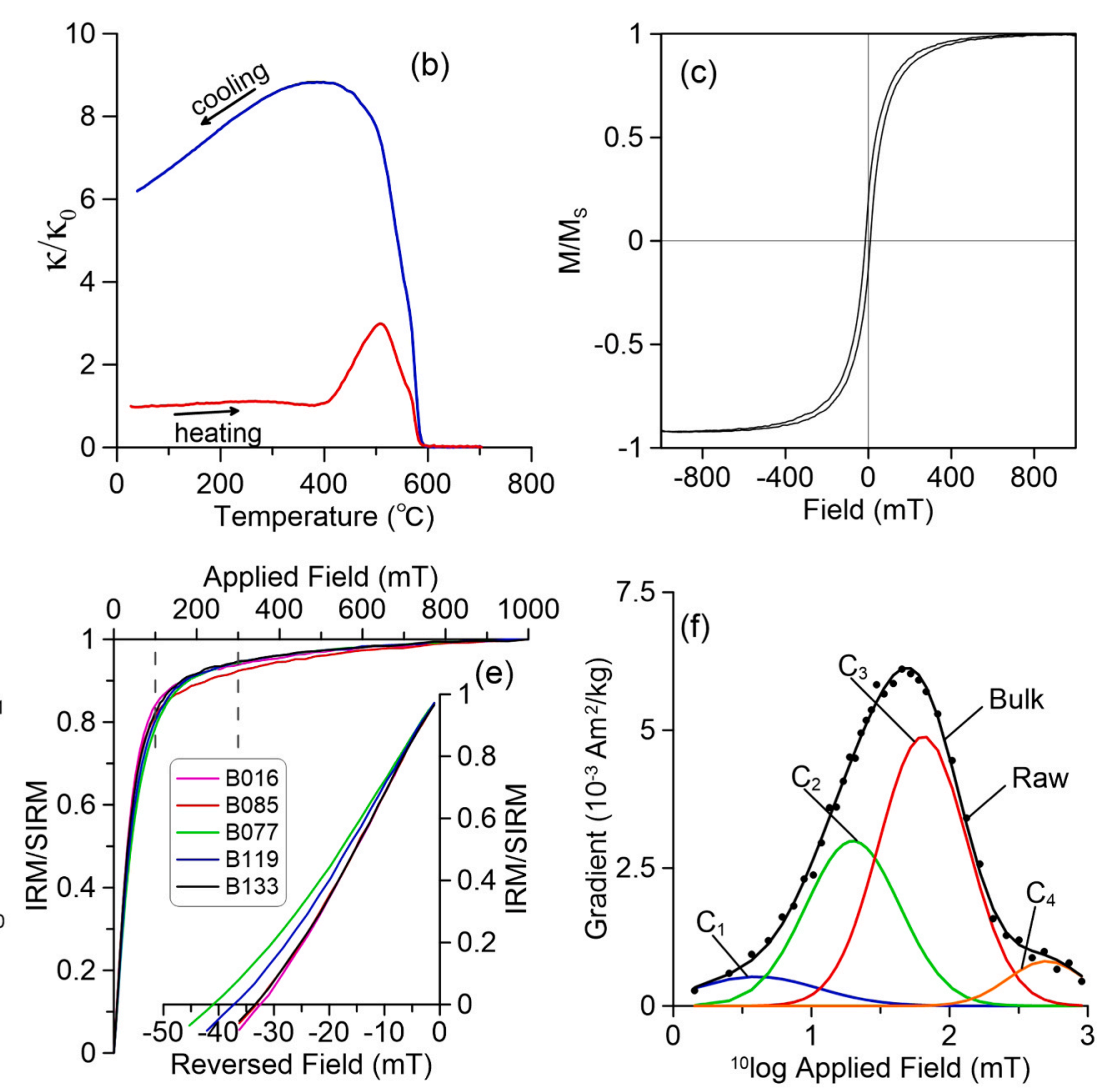

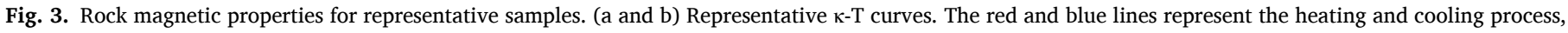

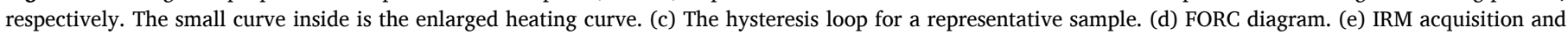

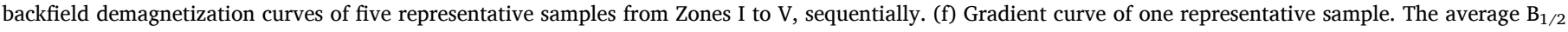

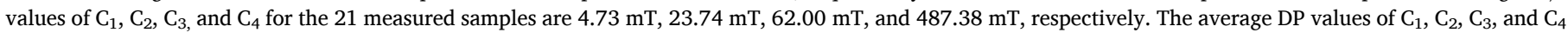

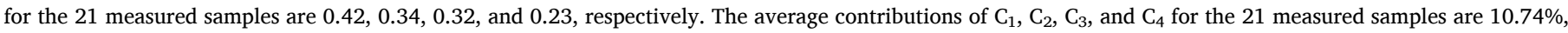

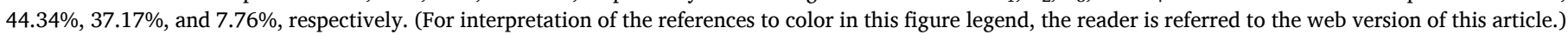

\subsubsection{Spatial distribution of magnetic parameters}

Magnetic minerals are mainly concentrated in Zones I, II, IV, and VI, as reflected by the relatively high values of $\chi_{\text {If }}$ in these regions (Fig. 2). The highest SIRM, and HIRM values; and the lowest $\chi_{\mathrm{fd}}, \chi_{\mathrm{ARM}}, \chi_{\mathrm{ARM}} /$ SIRM, and $S_{-100}$ values occur in Zone I, indicating that coarse magnetic minerals with relatively high coercivity predominate in this region. Zone II, the mud area, contains the highest content of the finest magnetic minerals, reflected by the highest $\chi_{\mathrm{fd}}$, and intermediate $\chi_{\mathrm{ARM}}$ and $\chi_{\mathrm{ARM}} /$ SIRM values (Fig. 2 ). Zone IV has the highest $\chi_{\text {ARM }}, \chi_{\text {ARM }} / S I R M$, and $S_{-100}$ values, and intermediate $\chi_{\text {If }}$ and SIRM values, implying the lowcoercivity, fine-grained magnetic minerals predominate in this region. Magnetic content decreases from Zone II to Zones III and V, reflected by the distribution patterns of $\chi_{l f}, \chi_{\mathrm{fd}}, \chi_{\mathrm{fd}} \%$, SIRM, and HIRM (Fig. 2). $S_{-100}$ gradually increases towards the sea.

\subsection{HM concentrations and the contamination assessment}

Since the distribution characteristics of $\mathrm{Co}, \mathrm{Cr}, \mathrm{Ni}, \mathrm{Cu}$, and $\mathrm{Zn}$ are similar, we merely present the contour map of Co for demonstration purpose (Fig. 5), and other contour maps are illustrated in Fig. S2. In general, the ranges (average values) of $\mathrm{Co}, \mathrm{Cr}, \mathrm{Ni}, \mathrm{Cu}, \mathrm{Zn}, \mathrm{Cd}$, and $\mathrm{Pb}$ are 17.42-4.90 (9.07) mg/kg, 115.03-29.23 (57.93) mg/kg, 46.65-11.97 (23.92) $\mathrm{mg} / \mathrm{kg}, 34.77-7.18(15.88) \mathrm{mg} / \mathrm{kg}, 98.53-29.13$ (52.05) $\mathrm{mg} / \mathrm{kg}$, $0.84-0.18(0.43) \mathrm{mg} / \mathrm{kg}$, and $39.89-7.77(15.90) \mathrm{mg} / \mathrm{kg}$, respectively. The contents of $\mathrm{Co}, \mathrm{Cr}, \mathrm{Ni}, \mathrm{Cu}, \mathrm{Zn}$, and $\mathrm{Pb}$ are ranked as Zones II, IV, I, III, and $\mathrm{V}$, respectively (Fig. $5 \mathrm{a}$ and c). The elements $\mathrm{Co}, \mathrm{Cr}, \mathrm{Ni}, \mathrm{Cu}$, and $\mathrm{Zn}$ are the most enriched in the southern Zone II, between the Guangli, Zimai, and Xiaoqing Rivers along the southwestern bay and the YRE. In contrast, $\mathrm{Pb}$ is the most enriched in the northern Zones II and VI, close to the modern and abandoned YREs. The contents of $\mathrm{Co}, \mathrm{Cr}, \mathrm{Ni}, \mathrm{Cu}, \mathrm{Zn}$, and $\mathrm{Pb}$ in the southwestern and northeastern Zone VI are close to Zones I and II, respectively (Fig. 5 a and c). Cadmium content varies slightly in Zones I, II, III, and V, and is almost invariant in Zone IV. The highest Cd occurs in the southern bay (Fig. 5b). PLI is consistent with the spatial pattern of Co, and the high PLI values appear in the Xiaoqing River estuary, the northern mud area, and the northeastern Zone VI (Fig. 5d).

The contents of $\mathrm{Co}, \mathrm{Cr}, \mathrm{Ni}, \mathrm{Cu}, \mathrm{Zn}, \mathrm{Cd}$, and $\mathrm{Pb}$ in Zone II are the highest, followed by Zone IV (Fig. 6). In Zone II, the contents of $\mathrm{Co}, \mathrm{Cr}$, $\mathrm{Ni}, \mathrm{Cu}, \mathrm{Zn}, \mathrm{Cd}$, and $\mathrm{Pb}$ are $24 \%, 34 \%, 86 \%, 26 \%, 53 \%, 100 \%$, and $7 \%$ higher than their corresponding background values of Shandong Province. Contents of $\mathrm{Cu}, \mathrm{Co}$, and $\mathrm{Pb}$ in most samples are lower than the background values. The contents of $\mathrm{Cr}, \mathrm{Ni}$, and $\mathrm{Zn}$ in most samples (except Zone II) are lower than the background values. For all samples, $\mathrm{Cd}$ content is generally higher than the background value. The range of PLI is 0.59-1.56, implying an unpolluted to the moderately polluted environment in the LB. By contrast, Zones II and IV exhibit the highest and second-highest PLI values, respectively, suggesting a relatively severe HM pollution in muddy areas.

\subsection{Correlations among grain sizes, magnetic parameters, and HMs}

$\chi_{\mathrm{lf}}, \mathrm{SIRM}$, and HIRM are positively correlated with all elements and PLI, indicating the coexistence of magnetic minerals and elements in total (Table 2). Notably, $\chi_{\mathrm{lf}}$, SIRM, and HIRM are positively correlated with clay and silt contents in Zones II-V, but the relationships are completely opposite in Zones I and VI (Fig. $7 \mathrm{~b}, \mathrm{f}$ and $\mathrm{g}$ ). There is no apparent relationship between $S_{-100}$ and grain sizes (Fig. 7i, Table 2). There are good correlations among $\chi_{\mathrm{fd}}, \chi_{\mathrm{fd}} \%, \chi_{\mathrm{ARM}}, \chi_{\mathrm{ARM}} / \mathrm{SIRM}$, clay, silt, 

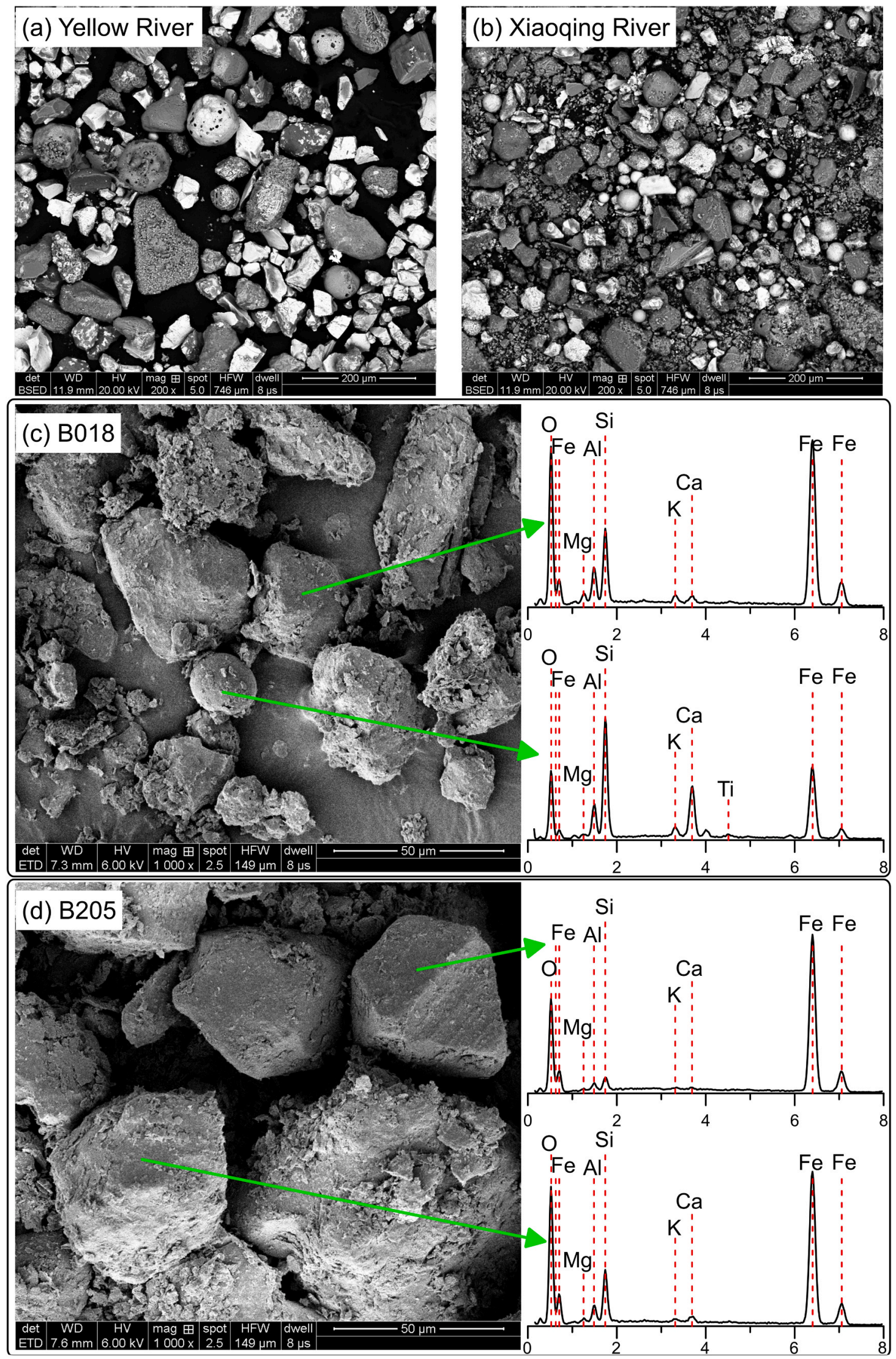

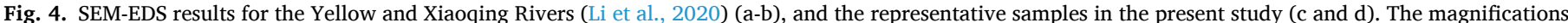

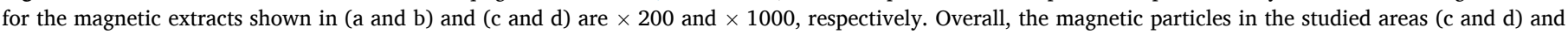

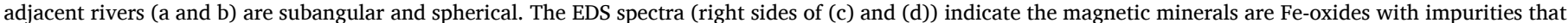
consist of $\mathrm{K}, \mathrm{Ca}, \mathrm{Al}, \mathrm{Si}, \mathrm{Mg}$, and $\mathrm{Ti}$. 


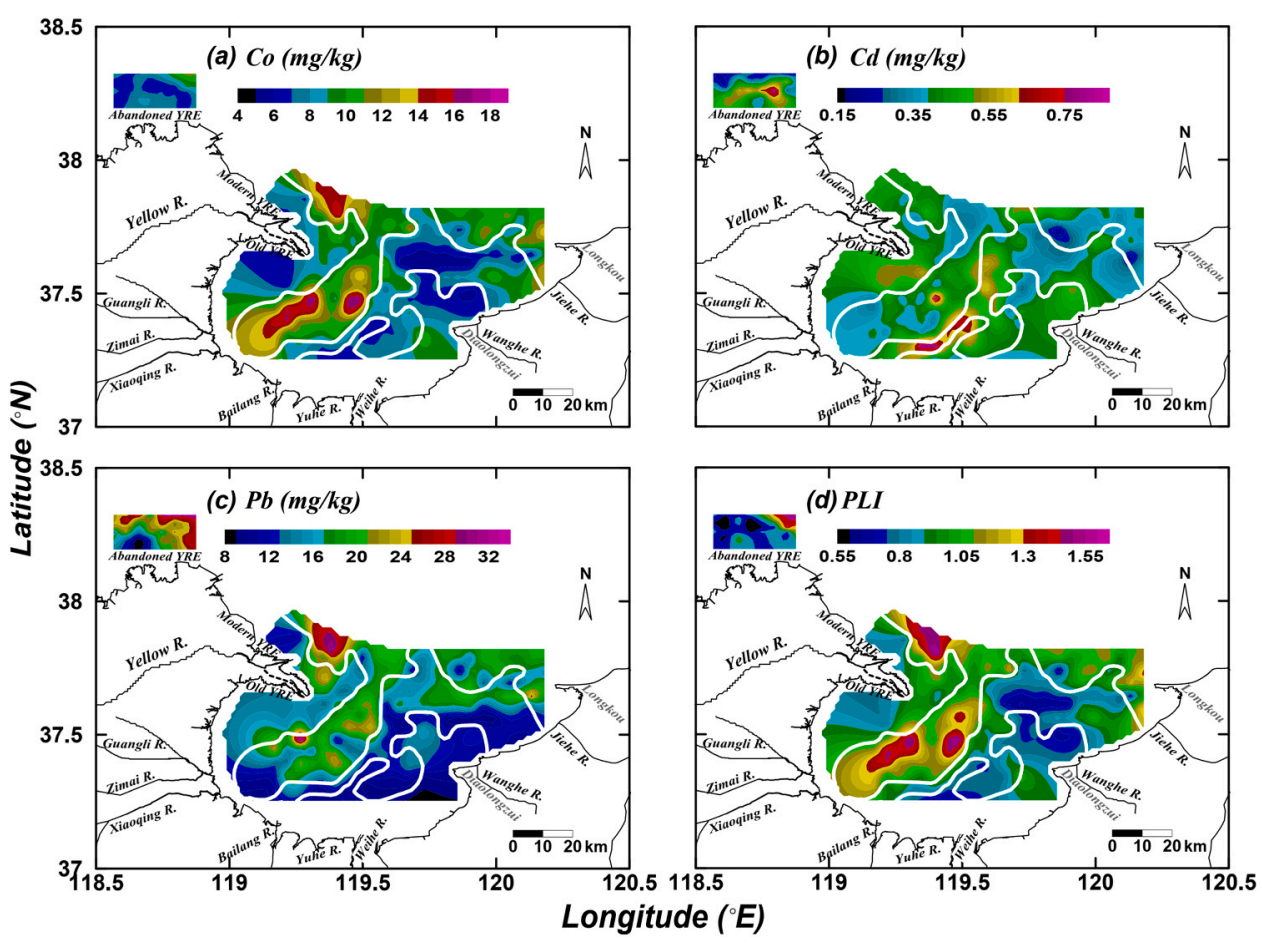

Fig. 5. Contour maps of Co (a), Cd (b), Pb (c), and PLI (d).

PLI, and the elemental contents of $\mathrm{Co}, \mathrm{Cr}, \mathrm{Ni}, \mathrm{Cu}, \mathrm{Zn}$, and $\mathrm{Pb}$ (Table 2, Fig. 7). Unlike other elements, Cd is negatively correlated to $\chi_{\mathrm{fd}}, \chi_{\mathrm{fd}} \%$, $\chi_{\text {ARM, }} \chi_{\text {ARM }} / S_{\text {SIRM }} S_{-100}$, clay, and silt, but it is positively correlated to HIRM and sand.

\section{Discussions}

\subsection{Sources of magnetic minerals and heavy metals}

Magnetic minerals in the studied sediments contain the features of detrital substances instead of magnetosomes or iron sulfides. It is because of the low values of SIRM/ $\chi_{\text {lf }}(8.75-14.04 \mathrm{kA} / \mathrm{m})$ and $\mathrm{Mrs} / \chi_{\mathrm{lf}}$ (10.26-22.04 kA/m) (Maher, 2007; Roberts, 1995; Roberts and Turner, 1993), the featured FORC diagram patterns (Fig. 3d) (Roberts et al., 2018), and the identification plot delineated by SIRM/ $\chi_{\text {If }}$ versus $B_{\mathrm{cr}}$ (Fig. 7a) (Peters and Thompson, 1998). The subangular magnetic minerals are typically from the natural environment, while the spherical ones are from human activities (Fig. 4) (Zhang et al., 2011). The magnetic minerals in the LB and YRE are similar to those in the Chinese Loess Plateau (CLP) in north-central China (Li et al., 2020, Yang et al., 2000; Zhang et al., 1990b), because the materials carried by YR are mostly from the CLP to the LB (Heller and Liu, 1984; Liu et al., 2015; Liu et al., 1992; Ren and Shi, 1986; van Velzen and Dekkers, 1999; Zhang et al., 1990a). In addition, several local streams along the southern LB coast also supply the coastal area of the LB, albeit to a small degree (Compiling Committee of Records of China Bays, 1991; Li et al., 2020; Wang et al., 2010). Therefore, magnetic minerals undergo the same surficial process with the weathering-controlled HMs, and the variations in magnetic parameters are related to the changes in HMs. This was supported by the positive correlations between fine-grained magnetic minerals and most HMs (As, Cd, Co, Cr, Ni, Pb, and Zn) in the core Z07 (Chen et al., 2020).

Principal component analysis (PCA) was used to classify the HMs, magnetic parameters, and grain sizes. The first three principal components (PCs) together explain $86.83 \%$ of the variance in the data (PC1, 34.90\%; PC2, 31.96\%; PC3, 19.97\%) (Fig. 8). Contents of Cr, Co, Ni, Cu, and $\mathrm{Zn}$, and fine-grained sediment/magnetic mineral proxies (clay, silt, $\left.\chi_{\mathrm{fd}}, \chi_{\mathrm{fd}} \%, \chi_{\mathrm{ARM}}, \chi_{\mathrm{ARM}} / \mathrm{SIRM}\right)$ are positively associated with PC1, while sand is negatively associated with PC1. The five elements typically characterize the detrital minerals, and previous studies inferred that they are mainly from natural weathering processes of parent rocks in the Bohai Sea (Hu et al., 2017; Wang et al., 2017). The features of the HMs in adjacent rivers of the LB are useful to identify their sources. The sequential extraction of heavy metal fractionation in sediments is widely used to evaluate the contribution of different sources, and the residual and acid-soluble fractions represent the natural and anthropogenic sources, respectively (Gao et al., 2013; Xu et al., 2017; Zhuang and Gao, 2013, 2014). For most sediment samples in 9 rivers from the watershed of $\mathrm{LB}, \mathrm{Cr}, \mathrm{Ni}, \mathrm{Cu}$, and $\mathrm{Zn}$ are mainly concentrated in the residual fraction, except for $\mathrm{Cu}$ in the Jiehe, Wanghe, Weihe, and Xiaoqing Rivers, and $\mathrm{Cr}$ and $\mathrm{Zn}$ in the Jiehe, Jiaolai, and Xiaoqing Rivers (Xu et al., 2017). This confirms that $\mathrm{Cr}, \mathrm{Ni}, \mathrm{Cu}$, and $\mathrm{Zn}$ of PC1 are mainly from the natural source. Their spatial distributions are similar to clay and silt (Figs. 2 and 5), which implies that they are transported together with fine-grained sediments. This is consistent with previous studies reporting that metal concentrations generally increase with decreasing particle size for riverine (Brook and Moore, 1988; Singh et al., 1999) and estuarine sediments (Ackermann, 1980). Generally, smaller sediment/magnetic particles have larger ratios of surface area/volume and contain large amounts of $\mathrm{Fe} / \mathrm{Mn}$ oxides, thus they have greater ability to adsorb metals (Singh et al., 1999; Zhou et al., 2014). Consequently, PC1 is presumed to the natural-derived, suspended matters mainly from the YR and adjacent rivers.

PC2 exhibits a high positive factor loading for $\mathrm{Pb}$, and a negative factor loading for sand and Cd. Similar to PC1, PC2 is associated with the fine sediments deduced from the relative high loadings in clay, silt, $\chi_{\mathrm{fd}}$, $\chi_{\mathrm{fd}} \%, \chi_{\mathrm{ARM}}$, and $\chi_{\mathrm{ARM}} / \mathrm{SIRM}$ (Fig. 8). This coincides with the finding that $\mathrm{Pb}$ accumulates in fine-grained particles (e.g., aluminosilicate debris) in the Bohai Sea sediment (Zhang et al., 2020). Lead displays different spatial distributions compared with most elements (Fig. 5), probably because $\mathrm{Pb}$ in the Bohai Sea is an anthropogenic element that originated from coal combustion, vehicle exhausts, and mining of $\mathrm{Pb}-\mathrm{Zn}$ ores $\mathrm{Hu}$ et al., 2017). The enrichment of $\mathrm{Pb}$ in the YR sediments could be attributed to oil exploitation because the YR passes through the Shengli Oilfield (Liu et al., 2016). In the LB, atmospheric deposition accounts for 

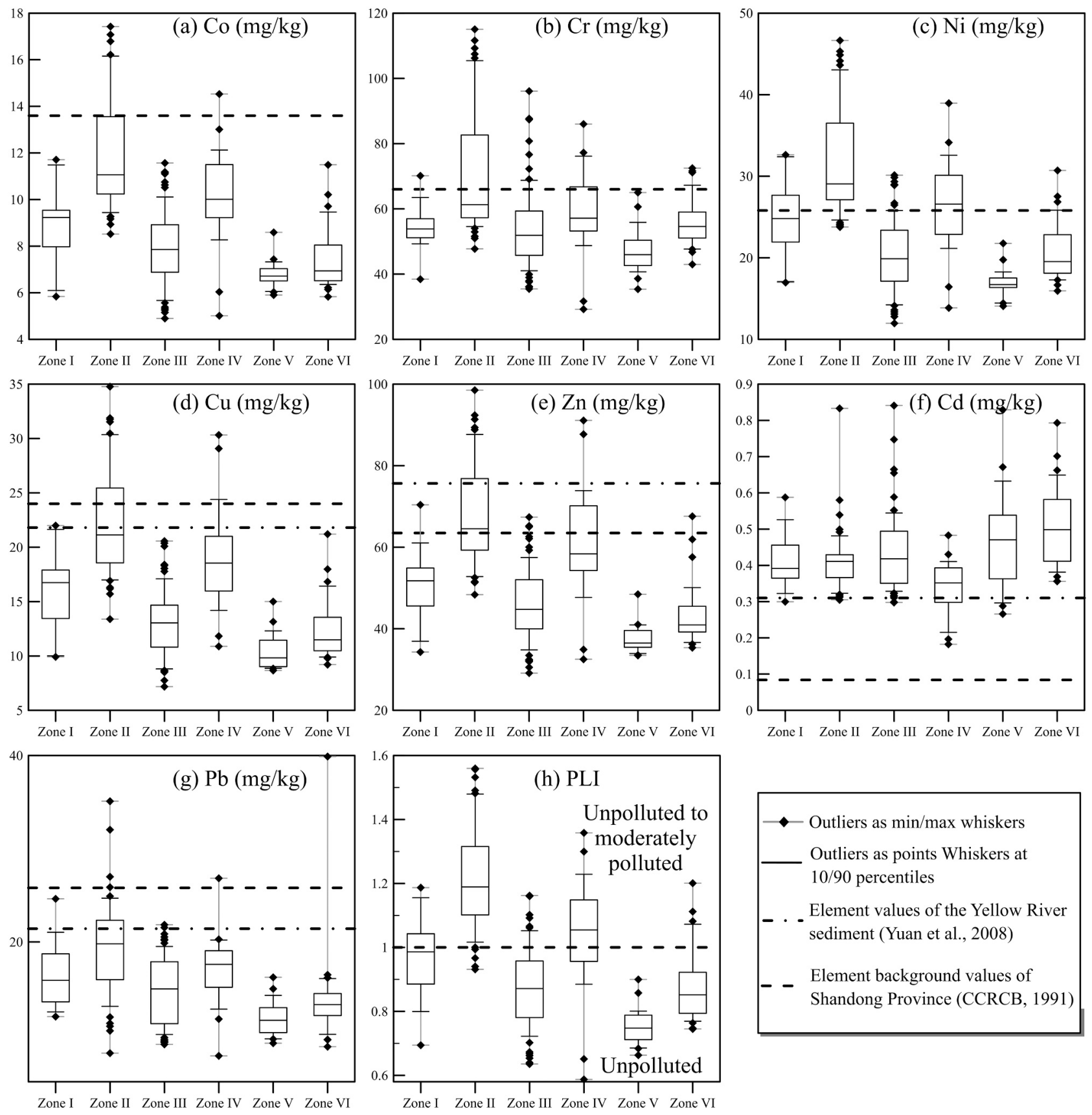

Fig. 6. Boxplots of contents of (a) Co, (b) Cr, (c) Ni, (d) Cu, (e) Zn, (f) Cd, (g) Pb, and (h) PLI.

Table 2

Pearson's correlation coefficients among magnetic parameters, HMs, and grain size contents.

\begin{tabular}{|c|c|c|c|c|c|c|c|c|c|c|c|}
\hline & $\chi_{\mathrm{lf}}$ & $\chi_{\mathrm{fd}}$ & $\chi_{\mathrm{fd}} \%$ & $\chi_{\text {ARM }}$ & $\chi_{\mathrm{ARM}} / \mathrm{SIRM}$ & SIRM & $\mathrm{S}_{-100}$ & HIRM & Clay & Silt & Sand \\
\hline Co & $0.523^{*}$ & $0.835^{*}$ & $0.793^{*}$ & $0.757^{*}$ & $0.561 *$ & $0.337^{\star}$ & 0.071 & $0.236^{*}$ & $0.610^{*}$ & $0.659^{*}$ & -0.718 \\
\hline $\mathrm{Cr}$ & $0.501^{*}$ & $0.540^{*}$ & $0.441^{*}$ & 0.470 * & $0.273^{*}$ & $0.366^{*}$ & -0.007 & $0.326^{*}$ & $0.327^{*}$ & $0.377^{*}$ & -0.401 \\
\hline $\mathrm{Ni}$ & $0.539 *$ & $0.826^{*}$ & $0.781^{*}$ & $0.736^{*}$ & $0.520^{*}$ & $0.396^{*}$ & 0.003 & $0.285^{*}$ & $0.601^{*}$ & $0.644^{*}$ & -0.704 \\
\hline $\mathrm{Cu}$ & $0.505^{*}$ & $0.860^{*}$ & $0.845^{*}$ & $0.803^{*}$ & $0.625^{*}$ & $0.343^{*}$ & 0.077 & $0.210^{*}$ & $0.670^{*}$ & $0.696^{*}$ & -0.770 \\
\hline $\mathrm{Zn}$ & $0.527^{*}$ & $0.826^{*}$ & $0.791^{*}$ & $0.797^{*}$ & $0.599 *$ & $0.355^{*}$ & 0.122 & $0.228^{*}$ & $0.618^{*}$ & $0.702^{*}$ & -0.750 \\
\hline $\mathrm{Cd}$ & $0.341 *$ & -0.204 * & $-0.403^{*}$ & $-0.318^{*}$ & -0.479 & $0.301 *$ & $-0.299^{*}$ & $0.475^{*}$ & $-0.318^{*}$ & $-0.380^{*}$ & 0.398 \\
\hline $\mathrm{Pb}$ & $0.355^{*}$ & $0.595^{*}$ & $0.601^{*}$ & $0.522^{*}$ & $0.410^{*}$ & $0.252^{*}$ & 0.025 & $0.183^{*}$ & $0.596^{*}$ & $0.467^{*}$ & -0.584 \\
\hline PLI & $0.631^{*}$ & $0.865^{*}$ & $0.794^{*}$ & $0.770^{*}$ & $0.528^{*}$ & $0.450^{*}$ & 0.009 & $0.358^{*}$ & $0.635^{*}$ & $0.657^{*}$ & -0.728 \\
\hline
\end{tabular}

" $\mathrm{p}<0.01$. Sample numbers of elements versus magnetic parameters, and elements versus grain sizes are 231, and 224, respectively. 

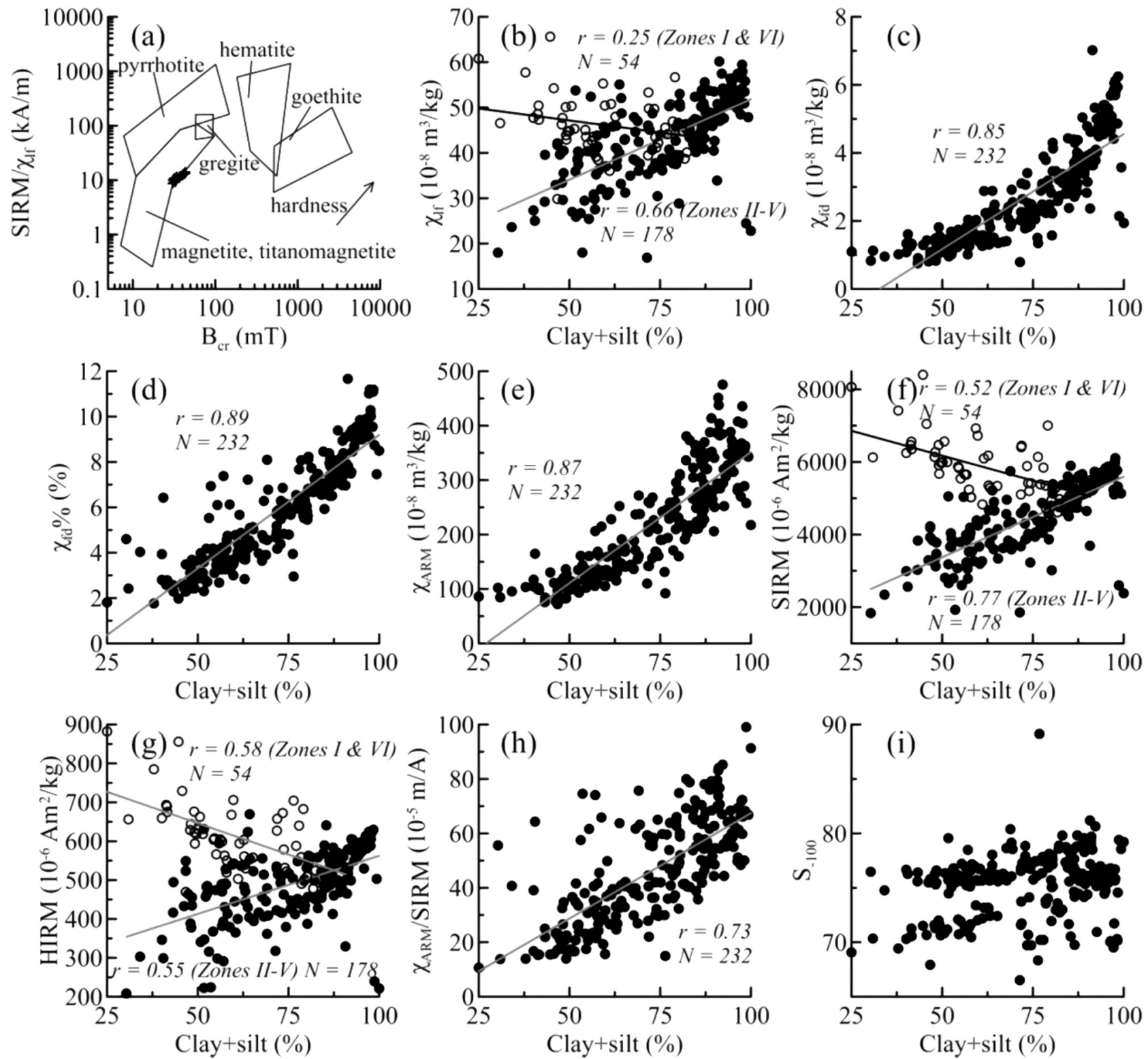

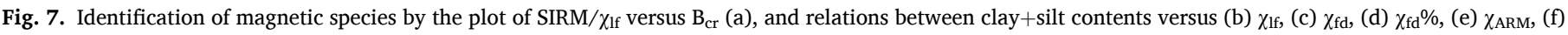
SIRM, (g) HIRM, (h) $\chi_{\mathrm{ARM}} / \mathrm{SIRM}$, and (i) $\mathrm{S}_{-100}$.

$30 \%$ for $\mathrm{Pb}$, while their contributions to $\mathrm{Cr}, \mathrm{Cu}, \mathrm{Zn}$, and $\mathrm{Cd}$ are only 0.7-3.4\% (Liang et al., 2018). In this sense, PC2 represents the suspended matters supplied by the anthropogenic activities through both the river and atmospheric inputs.

Cadmium, HIRM, SIRM, and $\chi_{\mathrm{lf}}$ are positively associated with PC3, while $S_{-100}$ and $\chi_{\text {ARM }} /$ SIRM are negatively associated with PC3 (Fig. 8). Cadmium in the LB sediments has observable acid-soluble fraction (Zhuang and Gao, 2014), which indicates the presence of the anthropogenic input. Cadmium content of most samples in the LB is higher than the YR sediment (Fig. 6f; Yuan et al., 2008), which implies the limited contribution of Cd from the YR. In the southwestern coastal LB, $\mathrm{Cd}$ contents in the river sediments are apparently higher than the marine sediments (Gao et al., 2015), so the rivers are perceived as the primary source of Cd (Zhuang and Gao, 2013). Cadmium in the LB sediments probably comes from phosphate fertilizers, alloying, electroplating, and dyeing industries (Zhang and Shan, 2008). Rivers feeding the southern bay pass through the important agricultural area, the big city Jinan, and the Weifang Port Industrial Zone (Xu et al., 2015). An earlier study revealed that the Xiaoqing River is more enriched in $\mathrm{Cd}$ and $\mathrm{Cr}$ than other rivers and lakes in Jinan (Zhang and Wang, 2010). Therefore, PC3 represents the input of wastewater from the southern LB coast river. The coexistence of Cd, HIRM, SIRM, and $\chi_{\text {If }}$ is probably due to the adsorption of Cd ions onto magnetic minerals, especially for hematite, as confirmed by previous studies (Christensen and Huang, 1999). The land on the south of LB is an important agricultural area, where more organic fertilizers were applied in recent years. The humic acid, a widely used additive in organic fertilizers, can promote the absorption of $\mathrm{Cd}$ on hematite in soils (Cowan et al., 1991; Davis and Bhatnagar, 1995). This probably caused the preferential absorption of $\mathrm{Cd}$ on hematite in the land and the adjacent sea area (Zones III and V). Chromium is slightly positive associated with PC3, implying the contribution from human activities to $\mathrm{Cr}$ in addition to the natural source.

\subsection{Sediment discharge and hydrodynamic effect cause the spatial differences in heavy metals}

Coarse-grained sediments (e.g., sand) from the YR settled in Zones I and VI because of the gravitational differentiation in the estuary $\mathrm{Hu}$ 

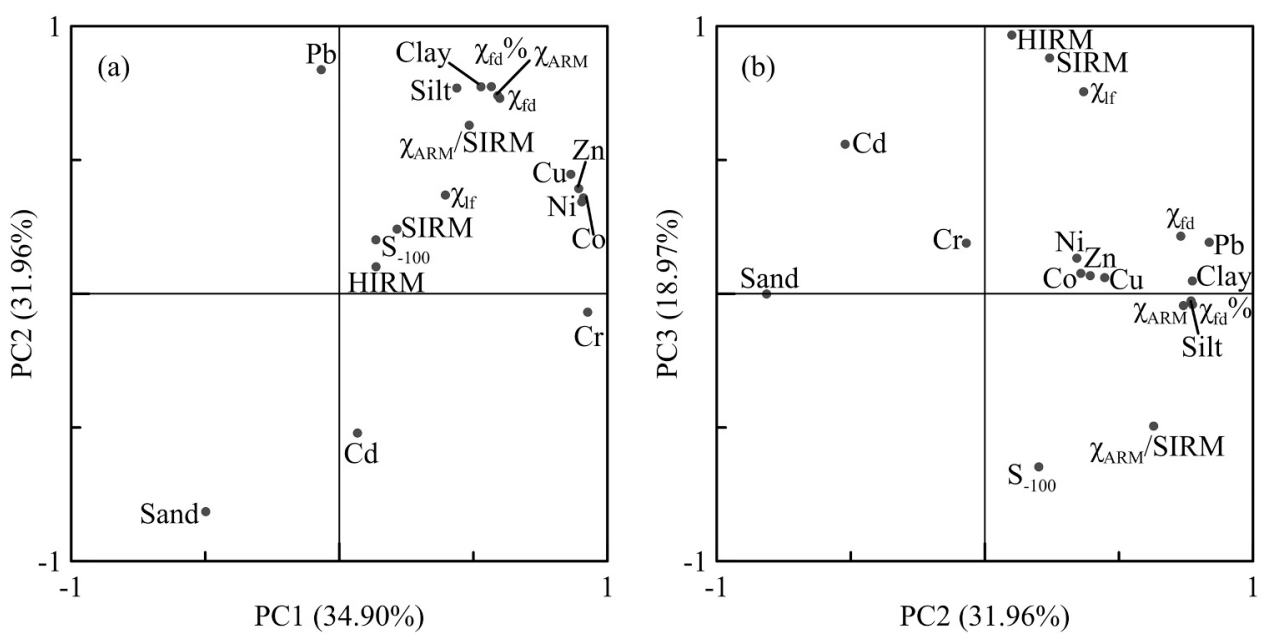

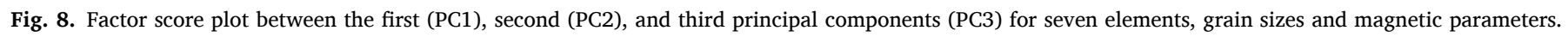

et al., 1994; Qin et al., 1985; Wu et al., 1994). The transport process promotes the settlement of coarse-grained magnetic minerals, hematite, and Cd (Figs. 2f and 5b). Most clay, silt, and fine-grained magnetic minerals with abundant $\mathrm{Co}, \mathrm{Cr}, \mathrm{Ni}, \mathrm{Cu}, \mathrm{Zn}$, and $\mathrm{Pb}$ are carried to Zone II because of the favorable currents (Qiao et al., 2010; Qin and Li, 1982) (Figs. 1c and 5a). The different distributions of $\mathrm{Cd}$ and other HMs should be partly ascribed to the adsorb behavior of minerals on elements because $\mathrm{Cd}$ is preferentially adsorbed by hematite, while other HMs are adsorbed by fine-grained magnetic minerals (as mentioned above). The different source of $\mathrm{Cd}$ also makes it a different distribution behavior with other HMs.

Although the $\mathrm{Co}, \mathrm{Cr}, \mathrm{Ni}, \mathrm{Cu}, \mathrm{Zn}$, and $\mathrm{Pb}$ in Zone IV are also controlled by the fine-grained fractions (clay and silt) (Fig. 5), indicating the influences of suspended matters, the source of the HMs in Zone IV is different from Zone II. Compared with Zone II, Zone IV contains more SSD and less SP magnetic grains (Fig. 2, S1). Previous studies indicated that Zone IV is supplied by sediments from both the YR and the adjacent rivers (e.g., Jiehe River) in the east coast (Fig. 1) according to the comparisons of magnetic parameters (Li et al., 2020). The Jiehe River flows through the Zhaoyuan County with a long history of gold mining, hence its water and sediments contain higher $\mathrm{Cu}, \mathrm{Pb}, \mathrm{Zn}, \mathrm{Ni}, \mathrm{Cr}$, and $\mathrm{Cd}$ contents than other rivers along the LB (Xu et al., 2013). The contents of $\mathrm{Co}, \mathrm{Cr}, \mathrm{Ni}, \mathrm{Cu}, \mathrm{Zn}$, and $\mathrm{Pb}$ on the northern side of Jiehe River (Zone IV) are higher than the southern side (Zone III) (Fig. 5). This is because Zone IV receives the Jiehe River materials carried by the northward current along the eastern LB coast and the YR materials carried by the anti-clock circulation (Fig. 1c).

Zones III and V contain the lowest contents of magnetic minerals and $\mathrm{Co}, \mathrm{Cr}, \mathrm{Ni}, \mathrm{Cu}, \mathrm{Zn}$, and $\mathrm{Pb}$, since the regions receive fewer suspended matters from rivers because of the weaker flow velocity. The enrichment of $\mathrm{Cd}$ in Zones III and V is probably caused by the northward water current (Fig. 1c) (Wang et al., 2010), and the higher Cd concentration in the coastal rivers (Gao et al., 2015). The Cd contents of the coastal rivers are 1.2 and 1.9 times higher than the coastal marine sediments in summer and autumn, respectively. So, the discharge of wastewater, in addition to the hydrodynamic effects, can interpret the distribution of Cd.

\subsection{Distributions of heavy metals affected by seasonal factors}

The studied samples collected in the top layer of $\sim 5 \mathrm{~cm}$ correspond to 3-5 years, according to the sedimentation rate (Qiao et al., 2017). Whilst river discharges can change seasonally, the distributions of most HMs are relatively consistent in different seasons, as compared with the studies using samples collected from other seasons. For instance, the enrichments of $\mathrm{Co}, \mathrm{Cr}, \mathrm{Ni}, \mathrm{Cu}, \mathrm{Zn}$, and $\mathrm{Pb}$ in Zones II and IV were also found by previous studies using samples collected in the summer of 2012 (Xu et al., 2015), and August and September of 2009 (Hu et al., 2017). The enrichment of HMs also presented in Zone I (close to the YRE) during the summer, probably due to the large sediment discharge from the YR in that time. Liu et al. (2004) conducted six field surveys (August, October, and December of 2002, and February, April, and June of 2003) to investigate the $\mathrm{Cu}, \mathrm{Zn}, \mathrm{Pb}$, and $\mathrm{Cd}$ contents of 15 sediment samples collected in the $\mathrm{LB}$. They discovered that the $\mathrm{Cu}, \mathrm{Zn}, \mathrm{Pb}$, and $\mathrm{Cd}$ contents in the sediment samples were 9.98-11.02 $\mu \mathrm{g} / \mathrm{L}, 34.66-35.02 \mu \mathrm{g} / \mathrm{L}$, 9.70-10.10 $\mu \mathrm{g} / \mathrm{L}$, and $0.12-0.17 \mu \mathrm{g} / \mathrm{L}$, respectively. Apparently, the variance of $\mathrm{Cd}$ is higher than $\mathrm{Cu}, \mathrm{Zn}$, and $\mathrm{Pb}$. These imply that the $\mathrm{Cu}, \mathrm{Zn}$, and $\mathrm{Pb}$ contents are relatively consistent, but the $\mathrm{Cd}$ content is changeable.

Similarly, Gao et al. (2015) reported that in the southwestern LB coast, the contents of $\mathrm{Cr}, \mathrm{Ni}, \mathrm{Cu}, \mathrm{Pb}$, and $\mathrm{Zn}$ in early summer (May-June, 2012) and autumn (September-October, 2012) are positively correlated, but the relationship was not suitable for Cd. Gao et al. (2015) inferred that the rainwater plays a vital role in the input of $\mathrm{Cd}$, as the sampling time in autumn is after the peak period of the rainy season. Our results also support the viewpoint because the Cd content in autumn 2012 in this study $(0.18-0.84 \mathrm{mg} / \mathrm{kg})$ was quite higher than that in summer $2012(0.058-0.25 \mathrm{mg} / \mathrm{kg}$ ) (Xu et al., 2015). Unlike autumn 2012, the area with the most enriched Cd appeared in Zone II in summer 2012 (Xu et al., 2015). Therefore, during the summer, the YR supplies a non-negligible $\mathrm{Cd}$ to the $\mathrm{LB}$, while during the autumn, rivers along the southern LB contribute more Cd to the LB through the input of wastewater.

\subsection{Possible magnetic proxies for monitoring heavy metals}

$\chi_{\mathrm{fd}}$ was selected as the magnetic proxy to monitor the contents of Co, $\mathrm{Ni}, \mathrm{Cu}$, and $\mathrm{Zn}$, and the PLI, because of the highest correlation coefficients (>0.8) among them (Table 2; Fig. 9). Notably, the present study implies that only the HMs from the natural sources can be monitored by the magnetic approach, which is different from other studies reporting that magnetic parameters can also indicate the anthropogenic HMs (Chaparro et al., 2017; Chen et al., 2020; Dong et al., 2014; Sebastian, et al., 2017; Yang et al., 2019; Zhu et al., 2016). The previous studies collected samples from the coast region or sediment core with a single source and a relatively stable depositional environment. In other study regions, such as the urban soils with the predominant traffic/industrial sources of pollution, the magnetic methods quickly delineate the metal-polluted area because magnetic minerals and HMs are both released from human activities (Jordanova et al., 2008; Karimi 

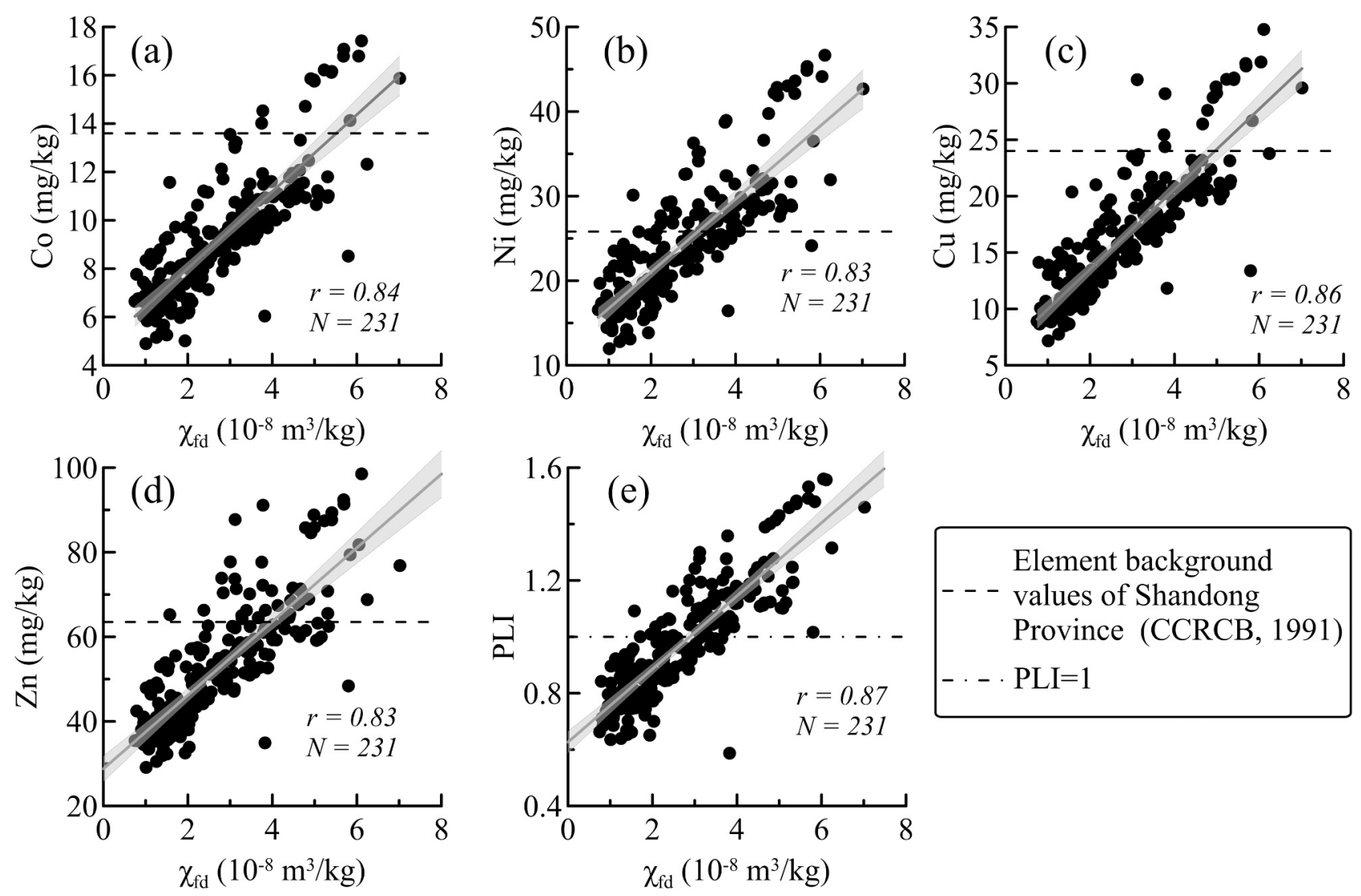

Fig. 9. Correlations of (a) Co versus $\chi_{\mathrm{fd}}$, (b) Ni versus $\chi_{\mathrm{fd}}$, (c) Cu versus $\chi_{\mathrm{fd}}$, (d) Zn versus $\chi_{\mathrm{fd}}$, and (e) PLI versus $\chi_{\mathrm{fd}}$.

et al., 2011; Wang and Qin, 2005). This implies that the depositional environment should be concerned when considering the usability of the magnetic method in monitoring HMs. The SP particles' content, indicated by $\chi_{\mathrm{fd}}$, is produced by the pedogenesis in the source region (Maher, 2007) and is enriched in fine sediment fractions (Table 2). Cobalt, $\mathrm{Ni}$, $\mathrm{Cu}$, and $\mathrm{Zn}$ could be associated with SP particles because the release of metals and SP particles' formation are both controlled by chemical weathering and pedogenesis, and both the four HMs and SP particles are transported and deposited with fine-grained particles. The unclear correlations between magnetic parameters and $\mathrm{Pb}, \mathrm{Cr}$, and $\mathrm{Cd}$ (Table 2) are ascribed to the additional influences of atmospheric deposition, human activities, and the discharge of seasonal wastewater, respectively. Therefore, the magnetic approach seems to be useless in rapidly detecting some metals in the regions with multi-sources and/or affected by multiple factors. Careful should be particularly taken when using the magnetic approach to monitor the HMs.

Compared with other mature chemical or spectroscopy methods, the magnetic parameters are relatively simple and quick to measure. The measurement is non-destructive because no chemistry reagent or other materials are involved. Although magnetic methods cannot completely replace the tests of HMs, the magnetic parameters are useful to delineate the high-risk area of HMs quickly, especially for $\mathrm{Co}, \mathrm{Ni}, \mathrm{Cu}$, and $\mathrm{Zn}$. It is evident that magnetic measurements could be used to give early pollution warnings. For instance, more measures should be taken to prevent and control the discharge of pollutants into the YRE and LB when the $\chi_{\mathrm{fd}}$ exceeds $3 \times 10^{-8} \mathrm{~m}^{3} / \mathrm{kg}$ corresponding to the PLI higher than 1 (Fig. 9e).

\section{Conclusion}

Magnetite, maghemite, and a small part of hematite coexist within surface sediments collected from the YRE, and LB. Magnetic properties of sediments can vary spatially due to the influences of the terrigenous input and water currents. Our results indicated that the concentrations of $\mathrm{Co}, \mathrm{Cr}, \mathrm{Ni}, \mathrm{Cu}, \mathrm{Zn}$, and $\mathrm{Pb}$ in almost all sampling sites are lower than the background values of the Shandong Province, but the Cd concentration is more enriched than the background value. The PCA results showed that $\mathrm{Co}, \mathrm{Cr}, \mathrm{Ni}, \mathrm{Cu}$, and $\mathrm{Zn}$ originate from natural weathering substances, while $\mathrm{Cd}$ and $\mathrm{Pb}$ are mainly from anthropogenic inputs. Both the natural-derived elements and $\mathrm{Pb}$ are transported by fine-grained particles, whereas Cd contains a different feature. We selected $\chi_{\mathrm{fd}}$ to rapidly monitor the contents of $\mathrm{Co}, \mathrm{Ni}, \mathrm{Cu}$, and $\mathrm{Zn}$, and PLI, due to the good positive correlations between them, and the synchronous process of SP particle formation and the release of HMs. Relationships between magnetic parameters and $\mathrm{Cd}, \mathrm{Cr}$, and $\mathrm{Pb}$ are unclear, probably due to the additional influences of atmospheric deposition, human activities, and the discharge of seasonal wastewater, respectively. Whilst magnetic parameters are not the ideal substitutes of HMs, they can be used to delineate the high-risk area of HMs rapidly.

\section{CRediT authorship contribution statement}

Mingkun Li performed the data analyses and wrote the manuscript; Shanying Zhu contributed significantly to the data analysis and manuscript preparation; Tingping Ouyang contributed to the conception of the study, discussed the data, and modified the manuscript; Jianhui Tang investigated the study region, collected specimens, completed part of the measurement and discussed the data, and revised the manuscript; Zhihua Tang helped perform the analysis with constructive discussions.

\section{Declaration of Competing Interest}

The authors declare that they have no known competing financial interests or personal relationships that could have appeared to influence the work reported in this paper. 


\section{Acknowledgments}

We thank the three anonymous reviewers for their thoughtful and constructive comments that deeply improved the manuscript. This work is supported by National Natural Science Foundation of China (41272384 and 41773138), the Key Research Programs of the Chinese Academy of Sciences (XDA11020401 and KZZD-EW-14), the Natural Science Foundation of Guangdong Province, China (2018B030311056 and 2019A1515110195), and the Postdoctoral Research Foundation of China (2019M652936). We are grateful to all colleagues for their assistance in sample collecting on board and processing in the lab. Professor Weiguo Wang and Miss Lili Chen from the Third Institute of Oceanography, Ministry of Natural Resources, generously provided experiment instrument VSM Micro Mag 3900 for this work. We thank Dr. Xiang Zhao of the Australian National University for his assistance in the FORC measurements. The authors would like to express their gratitude to EditSprings (https://www.editsprings.com/) for the expert linguistic services provided.

\section{Appendix A. Supporting information}

Supplementary data associated with this article can be found in the online version at doi:10.1016/j.jhazmat.2020.124579.

\section{References}

Abrajevitch, A., Font, E., Florindo, F., Roberts, A.P., 2015. Asteroid impact vs. Deccan eruptions: the origin of low magnetic susceptibility beds below the Cretaceous-Paleogene boundary revisited. Earth Planet. Sci. Lett. 430, 209-223.

Abrajevitch, A., Van der Voo, R., Rea, D.K., 2009. Variations in relative abundances of goethite and hematite in Bengal Fan sediments: climatic vs. diagenetic signals. Mar. Geol. 267, 191-206.

Ackermann, F., 1980. A procedure for correcting the grain size effect in heavy metal analyses of estuarine and coastal sediments. Environ. Technol. 1, 518-527.

Angulo, E., 1996. The Tomlinson Pollution Load Index applied to heavy metal, 'MusselWatch' data: a useful index to assess coastal pollution. Sci. Total Environ. 187, 19-56.

Bloemendal, J., King, J.W., Hall, F.R., Doh, S.J., 1992. Rock magnetism of Late Neogene and Pleistocene deep-sea sediments: relationship to sediment source, diagenetic processes, and sediment lithology. J. Geophys. Res. 97, 4361-4375.

Bloemendal, J., Lamb, B., King, J., 1988. Paleoenvironmental implications of rockmagnetic properties of Late Quaternary sediment cores from the eastern equatorial Atlantic. Paleoceanography 3, 61-87.

Brook, E.J., Moore, J.N., 1988. Particle-size and chemical control of As, Cd, Cu, Fe, Mn, $\mathrm{Ni}, \mathrm{Pb}$, and $\mathrm{Zn}$ in bed sediment from the Clark Fork river, Montana (USA). Sci. Total Environ. 76, 247-266.

Chaparro, M.A., Suresh, G., Chaparro, M.A., Ramasamy, V., Sundarrajan, M., 2017. Magnetic assessment and pollution status of beach sediments from Kerala coast (southwestern India). Mar. Pollut. Bull. 117, 171-177.

Cheng, Q., Lou, G., Huang, W., Li, X., 2017. Assessment and potential sources of metals in the surface sediments of the Yellow River Delta, Eastern China. Environ. Sci. Pollut. Res. 24, 17446-17454.

Chen, T., Liu, Q., Zheng, Y., Zhou, L., 2020. Correlation patterns between magnetic parameters and heavy metals of core sediments in the Yellow River Estuary and their environmental implications. Mar. Pollut. Bull. 160, 111590.

China National Environmental Monitoring Center, 1990. Chinese Elemental Background Values for Soils. Chinese Environmental Science Press, Beijing, p. 487.

Christensen, T.H., Huang, P.M., 1999. Solid phase cadmium and the reactions of aqueous cadmium with soil surfaces. In: McLaughlin, M.J., Singh, B.R. (Eds.), Cadmium in Soils and Plants. Springer, Dordrecht, pp. 65-96.

Compiling Committee of Records of China Bays, 1991. Records of China Bays 3rd Fascicule (The bays in north and east part of Shandong Peninsula). Ocean Press,, Beijing, p. 650.

Cowan, C.E., Zachara, J.M., Resch, C.T., 1991. Cadmium adsorption on iron oxides in the presence of alkaline-earth elements. Environ. Sci. Technol. 25, 437-446.

Davis, A.P., Bhatnagar, V., 1995. Adsorption of cadmium and humic acid onto hematite. Chemosphere 30, 243-256.

Day, R., Fuller, M., Schmidt, V., 1977. Hysteresis properties of titanomagnetites: grainsize and compositional dependence. Phys. Earth Planet. Inter. 13, 260-267.

Dearing, J., Bird, P., Dann, R., Benjamin, S., 1997. Secondary ferrimagnetic minerals in Welsh soils: a comparison of mineral magnetic detection methods and implications for mineral formation. Geophys. J. Int. 130, 727-736.

Dong, C., Zhang, W., Ma, H., Feng, H., Lu, H., Dong, Y., Yu, L., 2014. A magnetic record of heavy metal pollution in the Yangtze River subaqueous delta. Sci. Total Environ. 476, 368-377.

Dunlop, D., Özdemir, O., 1997. Rock Magnetism: Fundamentals and Frontiers. Cambridge University Press, Cambridge, p. 573.
Dunlop, D.J., 2002. Theory and application of the Day plot $\left(\mathrm{M}_{\mathrm{rs}} / \mathrm{M}_{\mathrm{S}}\right.$ versus $\left.\mathrm{H}_{\mathrm{cr}} / \mathrm{H}_{\mathrm{C}}\right) 1$. Theoretical curves and tests using titanomagnetite data. J. Geophys. Res. 107. EPM 4-1-EPM 4-22.

Gao, X., Li, P., Chen, C.T.A., 2013. Assessment of sediment quality in two important areas of mariculture in the Bohai Sea and the northern Yellow Sea based on acid-volatile sulfide and simultaneously extracted metal results. Mar. Pollut. Bull. 72, 281-288.

Gao, X., Zhuang, W., Chen, C.T.A., Zhang, Y., 2015. Sediment quality of the SW coastal Laizhou Bay, Bohai Sea, China: a comprehensive assessment based on the analysis of heavy metals. PLoS One 10, e0122190.

Gattacceca, J., Rochette, P., Scorzelli, R., Munayco, P., Agee, C., Quesnel, Y., Cournède, C., Geissman, J., 2014. Martian meteorites and Martian magnetic anomalies: a new perspective from NWA 7034. Geophys. Res. Lett. 41, 4859-4864.

Heller, F., Liu, T., 1984. Magnetism of Chinese loess deposits. Geophys. J. Int. 77, $125-141$.

Heslop, D., Dekkers, M.J., Kruiver, P.P., van Oorschot, I.H.M., 2002. Analysis of isothermal remanent magnetization acquisition curves using the expectationmaximization algorithm. Geophys. J. Int. 148, 58-64.

Hofman, J., Stokkaer, I., Snauwaert, L., Samson, R., 2013. Spatial distribution assessment of particulate matter in an urban street canyon using biomagnetic leaf monitoring of tree crown deposited particles. Environ. Pollut. 183, 123-132.

Hrouda, F., 2011. Models of frequency-dependent susceptibility of rocks and soils revisited and broadened. Geophys. J. Int. 187, 1259-1269.

Hu, C., Ji, Z., Wang, T., 1994. Characteristics of ocean dynamics and sediment diffusion in the Yellow River Estuary. J. Sediment Res. 4, 1-10.

Hu, N., Liu, J., Huang, P., Yan, S., Shi, X., Ma, D., 2017. Sources, geochemical speciation, and risk assessment of metals in coastal sediments: a case study in the Bohai Sea, China. Environ. Earth Sci. 76, 1-14.

Jordanova, N., Jordanova, D., Tsacheva, T., 2008. Application of magnetometry for delineation of anthropogenic pollution in areas covered by various soil types. Geoderma 144, 557-571.

Karimi, R., Ayoubi, S., Jalalian, A., Sheikh-Hosseini, A.R., Afyuni, M., 2011. Relationships between magnetic susceptibility and heavy metals in urban topsoils in the arid region of Isfahan, Central Iran. J. Appl. Geophys. 74, 1-7.

Kim, W., Doh, S.-J., Yu, Y., Lee, Y.I., 2013. Magnetic evaluation of sediment provenance in the northern East China Sea using fuzzy c-means cluster analysis. Mar. Geol. 337, 9-19.

Kruiver, P.P., Dekkers, M.J., Heslop, D., 2001. Quantification of magnetic coercivity components by the analysis of acquisition curves of isothermal remanent magnetisation. Earth Planet. Sci. Lett. 189, 269-276.

Liang, X., Tian, C., Zong, Z., Wang, X., Jiang, W., Chen, Y., Ma, J., Luo, Y., Li, J., Zhang, G., 2018. Flux and source-sink relationship of heavy metals and arsenic in the Bohai Sea, China. Environ. Pollut. 242, 1353-1361.

Liu, M., Fan, D., Bi, N., Sun, X., Tian, Y., 2019. Impact of water-sediment regulation on the transport of heavy metals from the Yellow River to the sea in 2015. Sci. Total Environ. 658, 268-279.

Liu, H., Liu, G., Wang, J., Yuan, Z., Da, C., 2016. Fractional distribution and risk assessment of heavy metals in sediments collected from the Yellow River. China Environ. Sci. Pollut. Res. 23, 11076-11084.

Liu, X., Shaw, J., Liu, T., Heller, F., Yuan, B., 1992. Magnetic mineralogy of Chinese loess and its significance. Geophys. J. Int. 108, 301-308.

Liu, Q., Sun, Y., Qiang, X., Tada, R., Hu, P., Duan, Z., Jiang, Z., Liu, J., Su, K., 2015. Characterizing magnetic mineral assemblages of surface sediments from major Asian dust sources and implications for the Chinese loess magnetism. Earth Planets Space $67,1-17$.

Liu, P., Wang, H., 2013. Flux and fate of the Yellow (Huanghe) River-derived materials to the sea: impacts of climate change and human activities. In: Bianchi, T.S., Allison, M.A., Cai, W.J. (Eds.), Biogeochemical Dynamics at Major River-Coastal Interfaces: Linkages with Global Change. Cambridge University Press, pp. 37-138.

Liu, F., Wang, H., Wang, D., 2004. Spatial distributions of heavy metals from the laizhou bay littoral wetland. Adv. Mar. Sci. 22, 486-492.

Li, H., Gao, X., Gu, Y., Wang, R., Xie, P., Liang, M., Ming, H., Su, J., 2018. Comprehensive large-scale investigation and assessment of trace metal in the coastal sediments of Bohai Sea. Mar. Pollut. Bull. 129, 126-134.

Li, H., Lin, L., Ye, S., Li, H., Fan, J., 2017. Assessment of nutrient and heavy metal contamination in the seawater and sediment of Yalujiang Estuary. Mar. Pollut. Bull. 117, 499-506.

Li, M., Zhu, S., Ouyang, T., Tang, J., He, C., 2020. Magnetic fingerprints of surface sediment in the Bohai Sea, China. Mar. Geol. 427, 106226.

Maher, B.A., 1986. Characterisation of soils by mineral magnetic measurements. Phys. Earth Planet. Inter. 42, 76-92.

Maher, B.A., 1988. Magnetic properties of some synthetic sub-micron magnetites. Geophys. J. Int. 94, 83-96.

Maher, B.A., 2007. Environmental magnetism and climate change. Contemp. Phys. 48, 247-274.

Ma, M., Hu, S., Cao, L., Appel, E., Wang, L., 2015. Atmospheric pollution history at Linfen (China) uncovered by magnetic and chemical parameters of sediments from a water reservoir. Environ. Pollut. 204, 161-172.

Milliman, J.D., Meade, R.H., 1983. World-wide delivery of river sediment to the oceans. J. Geol. 91, 1-21.

Ouyang, T., Tang, Z., Zhao, X., Tian, C., Ma, J., Wei, G., Huang, N., Li, M., Bian, Y., 2015. Magnetic mineralogy of a weathered tropical basalt, Hainan Island, South China. Phys. Earth Planet. Inter. 240, 105-113.

Peters, C., Thompson, R., 1998. Magnetic identification of selected natural iron oxides and sulphides. J. Magn. Magn. Mater. 183, 365-374.

Pike, C.R., Roberts, A.P., Verosub, K.L., 2001. First-order reversal curve diagrams and thermal relaxation effects in magnetic particles. Geophys. J. Int. 145, 721-730. 
Qiao, L., Bao, X., Wu, D., Wang, X., 2008. Numerical study of generation of the tidal shear front off the Yellow River Mouth. Cont. Shelf Res. 28, 1782-1790.

Qiao, S., Shi, X., Wang, G., Zhou, L., Hu, B., Hu, L., Yang, G., Liu, Y., Yao, Z., Liu, S., 2017. Sediment accumulation and budget in the Bohai Sea, Yellow Sea and East China Sea. Mar. Geol. 390, 270-281.

Qiao, S., Shi, X., Zhu, A., Liu, Y., Bi, N., Fang, X., Yang, G., 2010. Distribution and transport of suspended sediments off the Yellow River (Huanghe) Mouth and the nearby Bohai Sea. Estuar. Coast. Shelf Sci. 86, 337-344.

Qin, Y., Li, F., 1982. Study on the suspended matter of the sea water in the Bohai Gulf. Acta Oceanol. Sin. 4, 191-199.

Qin, Y., Zhao, Y., Zhao, S., 1985. Geology of the Bohai Sea. Science Press, Beijing.

Rao, Q., Sun, Z., Tian, L., Li, J., Sun, W., Sun, W., 2018. Assessment of arsenic and heavy metal pollution and ecological risk in inshore sediments of the Yellow River Estuary, China. Stoch. Environ. Res. Risk Assess. 32, 2889-2902.

Ren, M., Shi, Y., 1986. Sediment discharge of the Yellow River (China) and its effect on the sedimentation of the Bohai and the Yellow Sea. Cont. Shelf Res. 6, 785-810.

Roberts, A.P., 1995. Magnetic properties of sedimentary greigite $\left(\mathrm{Fe}_{3} \mathrm{~S}_{4}\right)$. Earth Planet. Sci. Lett. 134, 227-236.

Robertson, D., France, D., 1994. Discrimination of remanence-carrying minerals in mixtures, using isothermal remanent magnetisation acquisition curves. Phys. Earth Planet. Inter. 82, 223-234.

Roberts, A.P., Almeida, T.P., Church, N.S., Harrison, R.J., Heslop, D., Li, Y., Li, J., Muxworthy, A.R., Williams, W., Zhao, X., 2017. Resolving the origin of pseudosingle domain magnetic behavior. J. Geophys. Res.: Solid Earth 122, 9534-9558.

Roberts, A.P., Cui, Y., Verosub, K.L., 1995. Wasp-waisted hysteresis loops: mineral magnetic characteristics and discrimination of components in mixed magnetic systems. J. Geophys. Res. 100, 17909-17924.

Roberts, A.P., Pike, C.R., Verosub, K.L., 2000. First-order reversal curve diagrams: a new tool for characterizing the magnetic properties of natural samples. J. Geophys. Res. $105,28461-28475$.

Roberts, A.P., Turner, G.M., 1993. Diagenetic formation of ferrimagnetic iron sulphide minerals in rapidly deposited marine sediments, South Island, New Zealand. Earth Planet. Sci. Lett. 115, 257-273.

Roberts, A.P., Zhao, X., Harrison, R.J., Heslop, D., Muxworthy, A.R., Rowan, C.J., Larrasoana, J.C., Florindo, F.J., 2018. Signatures of reductive magnetic mineral diagenesis from unmixing of first-order reversal curves. J. Geophys. Res.: Solid Earth 123, 4500-4522.

Robinson, S.G., 1986. The late Pleistocene palaeoclimatic record of North Atlantic deepsea sediments revealed by mineral-magnetic measurements. Phys. Earth Planet. Inter. 42, 22-47.

Robinson, S.G., Sahota, J.T., 2000. Rock-magnetic characterization of early, redoxomorphic diagenesis in turbiditic sediments from the Madeira Abyssal Plain. Sedimentology 47, 367-394.

Rubio, B., Nombela, M., Vilas, F., 2000. Geochemistry of major and trace elements in sediments of the Ria de Vigo (NW Spain): an assessment of metal pollution. Mar. Pollut. Bull. 40, 968-980.

Salomons, W., Förstner, U., 1984. Metals in the hydrocycle. J. Appl. Ecol. 22.

Sebastian, T., Nath, B.N., Naik, S., Borole, D., Pierre, S., Yazing, A.K., 2017. Offshore sediments record the history of onshore iron ore mining in Goa State, India. Mar. Pollut. Bull. 114, 805-815.

Shepard, F.P., 1954. Nomenclature based on sand-silt-clay ratios. J. Sediment. Res. 24, 151-158.

Shu, J., Dearing, J.A., Morse, A.P., Yu, L., Yuan, N., 2001. Determining the sources of atmospheric particles in Shanghai, China, from magnetic and geochemical properties. Atmos. Environ. 35, 2615-2625.

Singh, A.K., Hasnain, S., Banerjee, D., 1999. Grain size and geochemical partitioning of heavy metals in sediments of the Damodar River - a tributary of the lower Ganga, India. Environ. Geol. 39, 90-98.

Spassov, S., Heller, F., Kretzschmar, R., Evans, M., Yue, L., Nourgaliev, D., 2003. Detrital and pedogenic magnetic mineral phases in the loess/palaeosol sequence at Lingtai (Central Chinese Loess Plateau). Phys. Earth Planet. Inter. 140, 255-275.

Tauxe, L., Mullender, T., Pick, T., 1996. Potbellies, wasp-waists, and superparamagnetism in magnetic hysteresis. J. Geophys. Res. 101, 571-583.

Thompson, R., Oldfield, F., 1986. Environmental Magnetism. Allen and Unwin, London, p. 227.

Tomlinson, D.L., Wilson, J.G., Harris, C.R., Jeffrey, D.W., 1980. Problems in the assessment of heavy-metal levels in estuaries and the formation of a pollution index. Helgol. Mar. Res. 33, 566-575.

van Velzen, A.J., Dekkers, M.J., 1999. Low-temperature oxidation of magnetite in loesspaleosol sequences: a correction of rock magnetic parameters. Stud. Geophys. Et. Geod. 43, 357-375.

Wang, Y., Ling, M., Liu, R., Yu, P., Tang, A., Luo, X., Ma, Q., 2017. Distribution and source identification of trace metals in the sediment of Yellow River Estuary and the adjacent Laizhou Bay. Phys. Chem. Earth 97, 62-70.
Wang, S., Liu, J., Li, J., Xu, G., Qiu, J., Chen, B., 2020. Environmental magnetic parameter characteristics as indicators of heavy metal pollution in the surface sediments off the Zhoushan Islands in the East China Sea. Mar. Pollut. Bull. 218, $108-117$.

Wang, X.S., Qin, Y., 2005. Correlation between magnetic susceptibility and heavy metals in urban topsoil: a case study from the city of Xuzhou, China. Environ. Geol. 49, $10-18$.

Wang, K., Shi, X., Cai, S., Qiao, S., Jiang, X., 2010. Distribution and provenance of the surface sediments of the Yellow River mouth and Laizhou Bay deduced from heavy minerals. Mar. Geol. Quat. Geol. 30, 1-8.

Wu, G., Xia, D., Wang, W., 1994. The relationships between the sediment distribution of present Yellow River's entrance to the sea and the ocean dynamic factors. Coast. Eng. 13, 24-30.

Xu, G., Liu, J., Pei, S., Gao, M., Hu, G., Kong, X., 2015. Sediment properties and trace metal pollution assessment in surface sediments of the Laizhou Bay, China. Environ. Sci. Pollut. Res. 15, 11634-11647.

Xu, L., Wang, T., Ni, K., Liu, S., Wang, P., Xie, S., Meng, J., Zheng, X., Lu, Y., 2013. Metals contamination along the watershed and estuarine areas of southern Bohai Sea, China. Mar. Pollut. Bull. 74, 453-463.

Xu, L., Wang, T., Wang, J., Lu, A., 2017. Occurrence, speciation and transportation of heavy metals in 9 coastal rivers from watershed of Laizhou Bay, China. Chemosphere 173, 61-68.

Yang, T., Liu, Q., Chan, L., Cao, G., 2007. Magnetic investigation of heavy metals contamination in urban topsoils around the East Lake, Wuhan, China. Geophys. J. Int. 171, 603-612.

Yang, S., Li, C., Zhu, J., Zhang, W., 2000. Provenance indicator of chemical fingerprint of magnetite from the Yangtze River and the Yellow River sediments. Geochimica 29, 480-484.

Yang, D., Wang, M., Lu, H., Ding, Z., Liu, J., Yan, C., 2019. Magnetic properties and correlation with heavy metals in mangrove sediments, the case study on the coast of Fujian, China. Mar. Pollut. Bull. 146, 865-873.

Yuan, H., Wang, Y., Gu, S., Lu, J., Zhou, H., Wan, X., 2008. Chemical forms and pollution characteristics of heavy metals in Yellow River sediments. Chin. J. Ecol. 27, 1966-1971.

Zhang, J., Gao, X., 2015. Heavy metals in surface sediments of the intertidal Laizhou Bay, Bohai Sea, China: distributions, sources and contamination assessment. Mar. Pollut. Bull. 98, 320-327.

Zhang, S., Guo, H., Zhang, S., Fan, H., Shi, J., 2020. Are oil spills an important source of heavy metal contamination in the Bohai Sea, China? Environ. Sci. Pollut. Res. 27, 3449-3461.

Zhang, J., Huang, W.W., Shi, M.C., 1990a. Huanghe (Yellow River) and its estuary: sediment origin, transport and deposition. J. Hydrol. 120, 203-223.

Zhang, C., Qiao, Q., Piper, J.D., Huang, B., 2011. Assessment of heavy metal pollution from a Fe-smelting plant in urban river sediments using environmental magnetic and geochemical methods. Environ. Pollut. 159, 3057-3070.

Zhang, H., Shan, B., 2008. Historical records of heavy metal accumulation in sediments and the relationship with agricultural intensification in the Yangtze-Huaihe region, China. Sci. Total Environ. 399, 113-120.

Zhang, L., Shao, H., 2013. Heavy metal pollution in sediments from aquatic ecosystems in China. CLEAN - Soil, Air, Water 41, 878-882.

Zhang, G., Wang, Z., 2010. Risk assessment of heavy metal pollution in shallow sediments of Jinan surface water. Environ. Sustain. Dev. 5, 40-44.

Zhang, J., Wei, W.H., Liu, M.G., Gu, Y.Q., Gu, Z.Y., 1990b. Element concentration and partitioning of loess in the Huanghe (Yellow River) drainage basin, north China. Chem. Geol. 89, 189-199.

Zhao, X., Heslop, D., Roberts, A.P., 2015. A protocol for variable-resolution first-order reversal curve measurements. Geochem. Geophys. Geosyst. 16, 1364-1377.

Zhou, G., Sun, B., Zeng, D., Wei, H., Liu, Z., Zhang, B., 2014. Vertical distribution of trace elements in the sediment cores from major rivers in east China and its implication on geochemical background and anthropogenic effects. J. Geochem. Explor. 139, 53-67.

Zhuang, W., Gao, X., 2013. Acid-volatile sulfide and simultaneously extracted metals in surface sediments of the southwestern coastal Laizhou Bay, Bohai Sea: concentrations, spatial distributions and the indication of heavy metal pollution status. Mar. Pollut. Bull. 76, 128-138.

Zhuang, W., Gao, X., 2014. Integrated assessment of heavy metal pollution in the surface sediments of the Laizhou Bay and the coastal waters of the Zhangzi Island, China: comparison among typical marine sediment quality indices. PLoS One 9, e94145.

Zhu, Z., Xue, J., Deng, Y., Lin, C., Liu, J., 2016. Trace metal contamination in surface sediments of intertidal zone from Qinhuangdao, China, revealed by geochemical and magnetic approaches: distribution, sources, and health risk assessment. Mar. Pollut. Bull. 105, 422-429. 